\title{
Magnetic Design and Experimental Evaluation of a Commercially Available Single Integrated Transformer in Three-phase LLC Resonant Converter
}

\author{
Mostafa Noah, Student Member, IEEE, Shota Kimura, Jun Imaoka, Member, IEEE, Wilmar Martinez, \\ Member, IEEE, Shun Endo, Masayoshi Yamamoto, Member, IEEE and Kazuhiro Umetani Member, \\ IEEE,
}

\begin{abstract}
Multi-phase topologies are preferably employed in power conversion systems to lessen the per phase circuit current, conduction losses, devices thermal stresses, and to reduce the output current ripples. Multi-phase LLC resonant dc/dc converter usually possess a number of magnetic cores equal to the number of phases. These magnetic cores are the major contributors to supply volume, weight, and size. For these reasons, circuit designers tend to select the topologies that have a minimal number of magnetic cores. In this paper, the authors aim to promote the industrial applications of the three-phase LLC resonant converter by integrating three transformers into a single, commercially available, magnetic core to reduce the volume, weight, and cost of the power converter. A comprehensive magnetic analysis for the three-phase integrated transformer is conducted. FEM Simulation and experimental tests are carried out to validate the proper operation of the integrated transformer utilized in a 390/12V$500 \mathrm{~W}$ prototype. Furthermore, the power losses distribution has been presented. The proposed integrated transformer has been proven efficient, and it realized a uniform thermal distribution along the core compared to the three discrete transformers.
\end{abstract}

Index Terms - Three-phase LLC resonant converter, Transformer design, dc/dc converter, Magnetic cores, Ferrite magnetic cores, Soft switching converters.

\section{INTRODUCTION}

\section{A. Research Motivation:}

$\mathrm{P}$ assive components are usually the biggest contributor to the power converter's volume, weight and cost. Driving the power devices with high switching frequency is one of the successful ways to downsize the magnetic components, especially with the advanced development of semiconductor devices such as: $\mathrm{SiC}$ and $\mathrm{GaN}$, which are capable of operating at high frequencies [1]-[3]. However, operating at high

Manuscript received November 18, 2017; revised May 13, 2018 and June 5 2018; accepted July 8, 2018.

M. Noah, J. Imaoka and M. Yamamoto are with the Power Electronics Lab of Nagoya University, Furo-cho, Chikusa-ku, Japan.

(email: mostafa.noah@ieee.org; imaoka@nuee.nagoya-u.ac.jp;

m.yamamoto@imass.nagoya-u.ac.jp)

S. Kimura and S. Endo are with the Department of Mechanical, Electrical and Electronic engineering, Shimane University, 1060 Nishikawatsu, Matsue,

Japan.

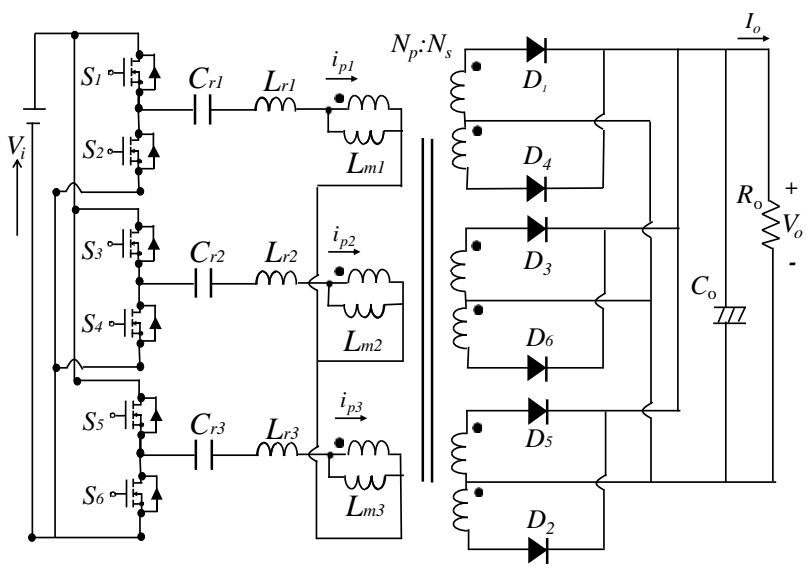

Fig. 1. Three-phase LLC resonant converter.

frequencies are limited to a certain range, where the converter overall losses are not dominated by switching losses. Moreover, higher frequencies lead to an increase in EMI/RFI noise which badly affects the converter operation.

As an alternative, designers are now turning towards integrating the magnetics, as another solution to reduce the size of the passive components. The expression "integrated magnetics" is used to describe a magnetic design whereby various inductive elements of a power converter are combined on a single magnetic core structure, and it has been applied to non-isolated buck and boost converters [4]-[9], and isolated DC/DC topologies such as Flyback and Forward converters [10]-[13]. LLC resonant converter is a popular topology among other power conversion circuits. However, adapting single phase LLC topology in high power applications comes with

(e-mail: shun.endo.shimane@gmail.com; shotak.j1@gmail.com).

W. Martinez is with KU Leuven, Electrical Engineering (ESAT) Department, Diepenbeek Campus, Agoralaan gebouw B bus 8 - box 15151, BE-3590 Diepenbeek, Belgium (e-mail: wilmar.martinez@kuleuven.be).

$\mathrm{K}$. Umetani is with the department of Electrical Engineering, Okayama University, Tsushimanaka-cho, Kita-ku, Okayama-shi, Japan. (e-mail: umetani@okayama-u.ac.jp). 
drawbacks. Since the current ripple stress on the output capacitor becomes severely high to handle, a large size output smoothing capacitor is needed to compensate the high output current ripples.

\section{B. Challenges of implementing multi-phase LLC resonant converter topologies}

There are two main drawbacks related to the size of the passive components, usually arise whilst employing multi-phase LLC resonant topologies. The first one is that the values of the resonant tank parameters are never exactly identical among the phases, thus each phase encounters a gain characteristic different than other phases, aggravating the output current ripples and hence, a larger output capacitor is needed to compensate the current imbalance [14]. The second drawback is that multi-phase LLC converter requires many magnetic components, which increase the volume, weight and cost of the converter. For a three-phase topology depicted in Fig.1, the former problem has been widely discussed in the literature. The authors of [15] have proposed a control scheme to compensate the gain difference between the phases by controlling the PFC's output voltage, and based on that adjusting the input voltage for each converter according to the peak value of the rectifier current. In [16] the current imbalance in the interleaved LLC converter has been tackled by phase-shift modulation (PSM). In [17], The three half-bridge LLC converter with a star connected primary transformer is presented, to reduce the output current ripples with the aid of a phase-shift control technique. However, applying control schemes tend to make the system more complex. Therefore, many studies have proposed other methods without employing control schemes. In [18] three current balancing transformers have been utilized in the three-phase LLC converter to equalize the currents between the phases. The primary side of the balancing transformer is connected in series with the resonant capacitor, while the secondary side is paralleled with the other phases. Nonetheless, adding three additional magnetic components costs the circuit additional power losses, adding extra volume, weight and cost to the converter. In [19]-[21] common passive components current sharing methods have been proposed to realize an equalized current between the phases. In the common inductor method, the resonant inductors of each phase are connected in parallel to form a common inductor, taking the current of each phase and redistributing it equally. However, having discrete resonant inductors is inevitably required in this method, integrating them in the transformer is not feasible. The aforementioned methods can minimize the output current ripples, and hence the output capacitor size can be effectively reduced.

\section{Magnetic integration in LLC converter: Literature review}

Integrated magnetics is one of the effective ways to downsize the magnetic components, in which multiple windings are placed on the same magnetic core.

In a single-phase LLC converter, it is popular to employ the leakage inductance between the primary and secondary winding of a transformer as a resonant tank inductance. In other words, to integrate the resonant inductor and the magnetizing inductance into the transformer structure.

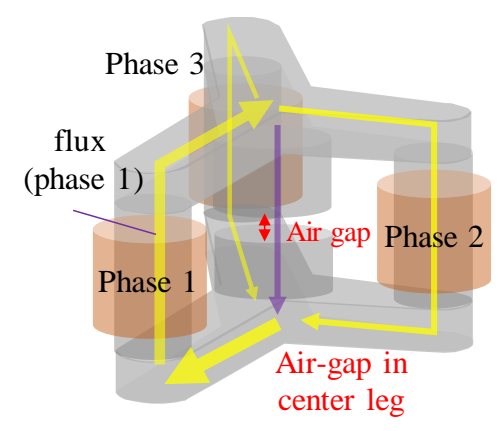

(a)

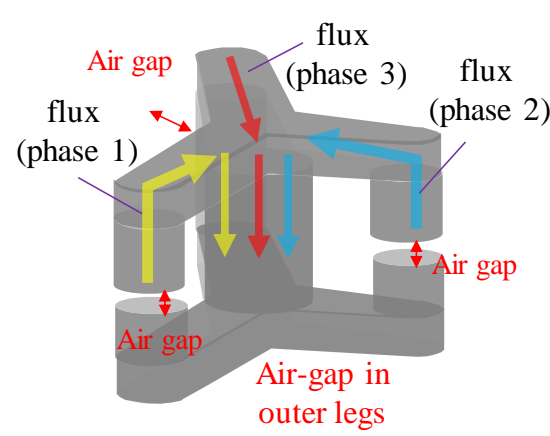

(b)

Fig.2 Spatial core integrated transformer (a) air-gap in the center leg reported in [29] (b) air-gap in three outer leg reported in [32]

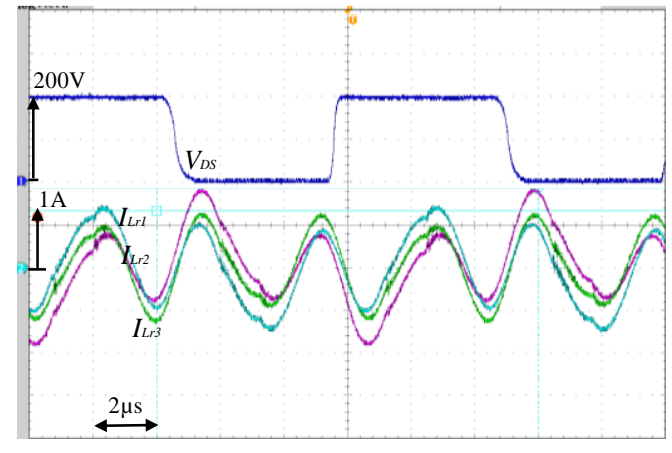

(a)

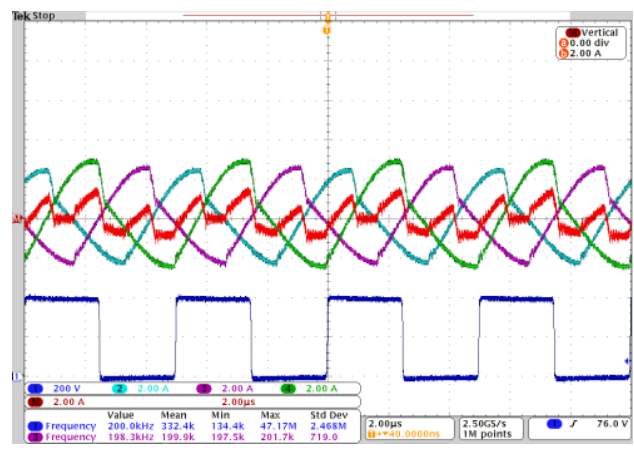

(b)

Fig.3 Resonant currents (a) In-phase resonant currents due to mutual induction reported in [29] (b) Resonant current and the unbalanced current (red waveform) reported in [32]. 
The magnetic integration within the single-phase topology is well documented in the literature [22]-[27]. For instance, in [22]-[26] an integrated magnetic design is proposed to integrate the magnetic components of the converter $\left(\mathrm{L}_{\mathrm{r}}, \mathrm{L}_{\mathrm{m}}\right)$ into one magnetic core. In [27], to improve the power density of the LLC converter, a further passive integration is proposed to integrate all passive components within the resonant tank, including the resonant capacitor $\mathrm{C}_{\mathrm{r}}$, into one single component - an integrated L-L-C-T. However, there is a drawback usually arises while applying magnetic integration techniques. For instance, it is difficult to control the value of the leakage inductance, which is extremely important to be designed precisely because it directly affects the converter gain curve. In [28], it has been revealed that in asymmetric core structures the primary and secondary leakage inductance may not be equal due to their location with respect to air gap.

On the other hand, recently some studies have been proposed to integrate the magnetics of the three phases of multi-phase LLC topologies. For instance, in [29], a customized four limbs core has been utilized, where the air-gap was inserted in the center leg as shown in Fig.2 (a). As a result, this converter encountered in-phase triple frequency resonant currents, as shown in Fig.3 (a). Inserting air gap in the center leg has led to an increment in the center leg reluctance, and hence a strong coupling between the three-phases occurred. In [30]-[31], Lagrangian dynamics has been employed to mathematically prove that it is possible to integrate the three-discrete transformers into a single core. The purpose of [32], is to propose a magnetic-based current balancing technique to improve the current sharing between the paralleled phases of three-phase LLC transformer with spatial core transformer. The proposed spatial core in this study is shown in Fig.2 (b). It has been reported in this study that when the air gaps are inserted in the outer leg, a similar performance to the three-discrete transformers can be realized using the spatial core, as shown in the resonant current waveforms of Fig.3 (b). Nonetheless the spatial core has three main drawbacks: i) The core is customized, and not suitable for mass production. ii) It may not be suitable to implement in industrial applications, as it is hard to package a spatial transformer. iii) The center leg unnecessarily utilizes additional magnetic material. With the purpose of promoting the industrial application, and as an alternative, the study in [33], has discussed utilizing a generic EE magnetic core. However, the magnetic analysis and the transformer design has not been reported.

This paper is a developed version of [33] which had been presented previously in a conference proceeding. The novelty is integrating the three-transformers into a single magnetic core, which is available in the market and easy to be implemented by engineers and researchers. In this discussion, a comprehensive magnetic analysis had been done to guide the engineers to have a better understanding of the magnetic behavior of the proposed integrated transformer, supported by a design example and FEA simulations. Moreover, additional experimental tests have been carried out to evaluate the proposed integrated transformer. Implementing the integrated transformer allows for a mass and size reduction of the magnetics. Furthermore, it has been proven that using the integrated transformer is efficient and it enables a uniform thermal distribution along the core.
The following discussion is divided into six sections. Section II presents the magnetic analysis of the integrated transformer, where the transformer is functioning as resonant and magnetizing inductors of the three-phases utilizing a single magnetic core. Section III presents a magnetic design example. The proper operation of the proposed integrated transformer is supported by various simulation and experimental tests in section IV. In the same section, efficiency and thermal tests have been conducted. Furthermore, the practical merits of employing the integrated transformer over the three-discrete transformers are reported. Finally, the conclusion is drawn in the last section.

\section{THREE-PHASE LLC INTEGRATED TRANSFORMER}

\section{A. Magnetic Analysis}

Magnetic integration is a technique whereby various inductive and transformer elements are advantageously combined on a single core. In this discussion, the windings of the three phases are advantageously combined into a single magnetic core. The designed magnetizing inductance is achieved, by placing air gaps in the three legs. The leakage inductance can be controlled

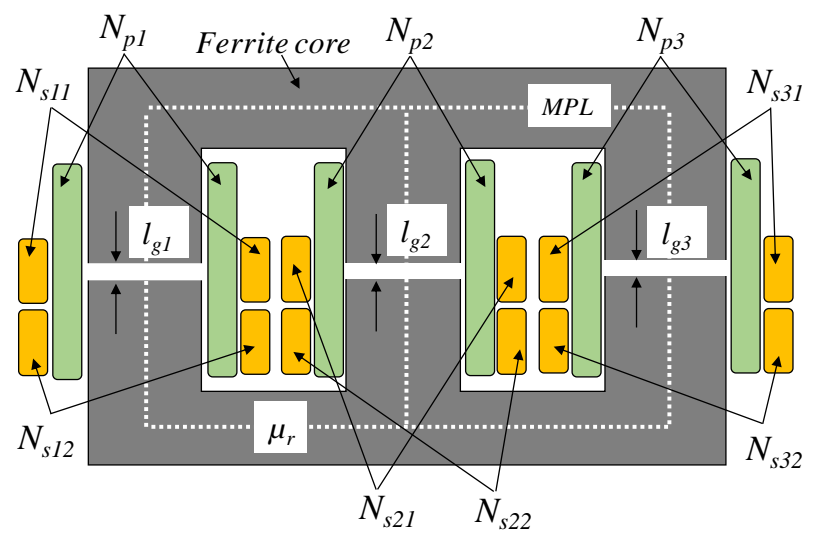

Fig. 4. Core structure of proposed integrated transformer.

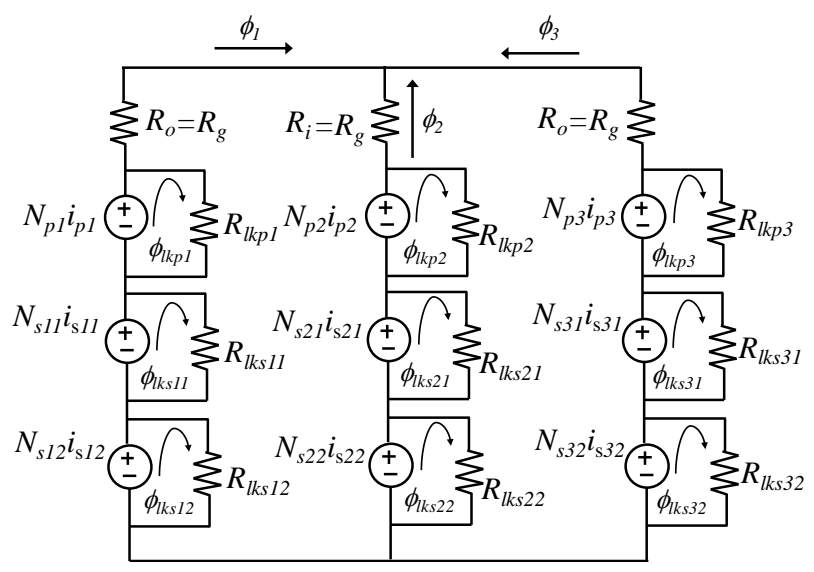

Fig. 5. Magnetic circuit model for the three-leg integrated transformer. 
by varying the distance between the primary and secondary winding on the same leg. An alternative way to alter the leakage is presented in Appendix A. The structure of the proposed integrated transformer is shown in Fig. 4. The primary number of turns of the three phases are $N_{p 1}, N_{p 2}, N_{p 3}$; and the secondary turns are $N_{s 11}, N_{s 12}, N_{s 21}, N_{s 22}, N_{s 31}$ and $N_{s 32}$. The magnetic circuit model of the three-leg transformer core is depicted in Fig.5. The reluctances of the outer and inner legs are denoted as $R_{o}$ and $R_{i}$, respectively.

The next step is to solve the magnetic circuit, and in order to simplify the analysis, the following assumptions have been made: a) The external leakage fluxes are ignored. b) For each phase, the two secondary center-tapped windings are assumed to be one winding with number of turns $N_{s 1}=N_{s 11}=N_{s 12}, N_{s 2}=$ $N_{s 21}=N_{s 22}$ and $N_{s 3}=N_{s 31}=N_{s 32}$. And currents $i_{s 1}=i_{s 11}+i_{s 12}, i_{s 2}$ $=i_{s 21}+i_{s 22}$ and $i_{s 3}=i_{s 31}+i_{s 32}$ for phases one, two and three; respectively. The simplified magnetic circuit model is shown in Table I. The magneto-motive forces follow Kirchhoff's voltage law and the fluxes follow Kirchhoff's current law; therefore, the following expressions can be obtained

$$
\begin{aligned}
& R_{o} \phi_{1}-R_{i} \phi_{2}=N_{p 1} i_{p 1}-N_{s 1} i_{s 1}-N_{p 2} i_{p 2}+N_{s 2} i_{s 2} \\
& R_{o} \phi_{1}-R_{o} \phi_{3}=N_{p 1} i_{p 1}-N_{s 1} i_{s 1}-N_{p 3} i_{p 3}+N_{s 3} i_{s 3} \\
& \phi_{1}+\phi_{2}+\phi_{3}=0
\end{aligned}
$$

Solving the preceding equations with respect to the fluxes, we obtain

$$
\begin{aligned}
& \phi_{1}=\frac{\left(N_{p 1} i_{p 1}-N_{s 1} i_{s 1}-N_{p 2} i_{p 2}+N_{s 2} i_{s 2}\right)}{R_{o}}+\frac{R_{i}}{R_{o}} \phi_{2} \\
& \phi_{3}=\frac{\left(N_{p 3} i_{p 3}-N_{s 3} i_{s 3}-N_{p 2} i_{p 2}+N_{s 2} i_{s 2}\right)}{R_{o}}+\frac{R_{i}}{R_{o}} \phi_{2} \\
& \phi_{2}=-\phi_{1}-\phi_{3}
\end{aligned}
$$

Substituting (6) in (4), (5), we obtain

$$
\begin{aligned}
& \phi_{1}=\left[\left(\frac{1+\alpha}{1+2 \alpha}\right) \frac{N_{p 1} i_{p 1}-N_{s 1} i_{s 1}}{R_{o}}\right. \\
& -\left(\frac{1}{1+2 \alpha}\right) \frac{N_{p 2} i_{p 2}-N_{s 2} i_{s 2}}{R_{o}} \\
& \left.-\left(\frac{\alpha}{1+2 \alpha}\right) \frac{N_{p 3} i_{p 3}-N_{s 3} i_{s 3}}{R_{o}}\right] \\
& \phi_{2}=\left[\left(\frac{2}{1+2 \alpha}\right) \frac{N_{p 2} i_{p 2}-N_{s 2} i_{s 2}}{R_{o}}\right. \\
& -\left(\frac{1}{1+2 \alpha}\right) \frac{N_{p 1} i_{p 1}-N_{s 1} i_{s 1}}{R_{o}} \\
& \left.-\left(\frac{1}{1+2 \alpha}\right) \frac{N_{p 3} i_{p 3}-N_{s 3} i_{s 3}}{R_{o}}\right] \\
& \phi_{3}=\left[\left(\frac{1+\alpha}{1+2 \alpha}\right) \frac{N_{p 3} i_{p 3}-N_{s 3} i_{s 3}}{R_{o}}\right. \\
& -\left(\frac{1}{1+2 \alpha}\right) \frac{N_{p 2} i_{p 2}-N_{s 2} i_{s 2}}{R_{o}} \\
& \left.-\left(\frac{\alpha}{1+2 \alpha}\right) \frac{N_{p 1} i_{p 1}-N_{s 1} i_{s 1}}{R_{o}}\right]
\end{aligned}
$$

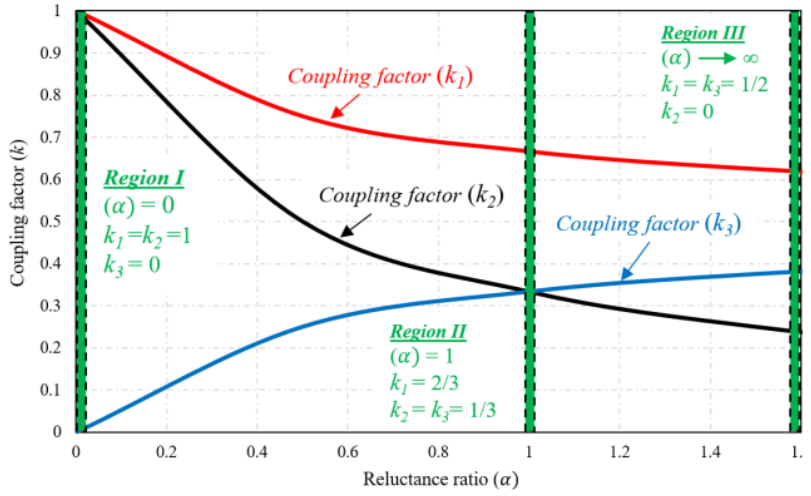

Fig. 6. Relationship between coupling factors and reluctance ratio $\alpha$.

Where $\alpha$ is a reluctance ratio factor $\alpha=\left(R_{i} / R_{o}\right)$

We propose a relevant coupling factors $k_{1}, k_{2}$ and $k_{3}$, where:

$k_{1}=\left(\frac{1+\alpha}{1+2 \alpha}\right)$

$k_{2}=\left(\frac{1}{1+2 \alpha}\right)$

$k_{3}=\left(\frac{\alpha}{1+2 \alpha}\right)$

Thereby (7), (8) and (9) can be rewritten as

$$
\begin{aligned}
\phi_{1}= & {\left[k_{1} \frac{N_{p 1} i_{p 1}-N_{s 1} i_{s 1}}{R_{o}}-k_{2} \frac{N_{p 2} i_{p 2}-N_{s 2} i_{s 2}}{R_{o}}\right.} \\
& \left.-k_{3} \frac{N_{p 3} i_{p 3}-N_{s 3} i_{s 3}}{R_{o}}\right] \\
\phi_{2}= & {\left[2 k_{2} \frac{N_{p 2} i_{p 2}-N_{s 2} i_{s 2}}{R_{o}}-k_{2} \frac{N_{p 1} i_{p 1}-N_{s 1} i_{s 1}}{R_{o}}\right.} \\
& \left.-k_{2} \frac{N_{p 3} i_{p 3}-N_{s 3} i_{s 3}}{R_{o}}\right]
\end{aligned}
$$

$$
\begin{aligned}
\phi_{3}= & {\left[k_{1} \frac{N_{p 3} i_{p 3}-N_{s 3} i_{s 3}}{R_{o}}-k_{2} \frac{N_{p 2} i_{p 2}-N_{s 2} i_{s 2}}{R_{o}}\right.} \\
& \left.-k_{3} \frac{N_{p 1} i_{p 1}-N_{s 1} i_{s 1}}{R_{o}}\right]
\end{aligned}
$$

The proposed relevant coupling factors $\left(k_{1}, k_{2}\right.$ and $\left.k_{3}\right)$ have a direct relationship with the reluctance ratio $(\alpha)$. This relationship is shown in Fig. 6. This chart represents three important regions, in which the reluctance ratio varies from a small to higher values. The three regions are well described in Table I. The equations describing the magnetic behavior of the integrated transformer in the three regions are listed in details in Table I.

In this discussion, the design is based on region II, this is to realize a symmetry between the three-phases, and therefore, $a c$ flux cancellation can be obtained. Moreover, in region II, a similar number of turns among the phases can be realized, since the reluctance of the three legs are equal. This is to achieve an 
equalized value of magnetizing inductance among the phases, which is necessary for the ZVS operation for the three-phase LLC resonant converter.

\section{B. Flux Density Equations}

The design methodology of a transformer incorporated in LLC resonant converter is different from conventional transformer. In the conventional transformer the leakage inductance is unavoidable and undesirable. However, in LLC resonant cconverter, the transformer's leakage inductance is unavoidable but desirable, and in many designs the leakage is intentionally increased, since it functions as a resonant inductance and it shall be precisely designed for a proper operation for the converter. The value of the leakage inductance is controlled by changing the distance between the primary and secondary windings.

On the other hand, the transformer's magnetizing inductance shall be designed carefully to achieve ZVS for the LLC converter. In this regards, the magnetizing inductance is controlled by placing air gaps in the transformer legs.

Usually, the transformer is designed to operate below the saturation, the maximum flux density can be obtained from Faraday's law as follows

$$
V_{i n T-i}=N_{p i} \frac{\phi_{i}}{T_{o n}}
$$

Where $V_{i n} T, N_{p}, \phi_{i}$ and $T_{o n}$ are the applied voltage on the transformer primary winding, primary number of turns, peakto-peak flux and switching on-time, respectively. $i=[1,2,3]$ and it denotes for the phase number.

Since the generated flux is only $a c$ flux, the maximum flux can be expressed as half the peak-to-peak flux as follows

$$
\phi_{m-i}=\frac{1}{2} \frac{V_{i n T-i} \cdot d \cdot T_{s}}{N_{p i}}
$$

Where $\phi_{m}, d$, and $T_{s}$ are the maximum flux, switching devices duty cycle and cycle time, respectively.

The maximum flux density can be expressed as

$$
B_{m-i}=\frac{\phi_{m-i}}{A_{c-i}}=\frac{1}{2}\left[\frac{V_{i n T-i} \cdot d}{N_{p i} \cdot f_{s} \cdot A_{c-i}}\right]
$$

Where $B_{m}, A_{c}$ and $f_{s}$ are the maximum flux density, the core cross section area and switching frequency.

TABLE I

THE MAGNETIC BEHAVIOR OF THE INTEGRATED TRANSFORMER

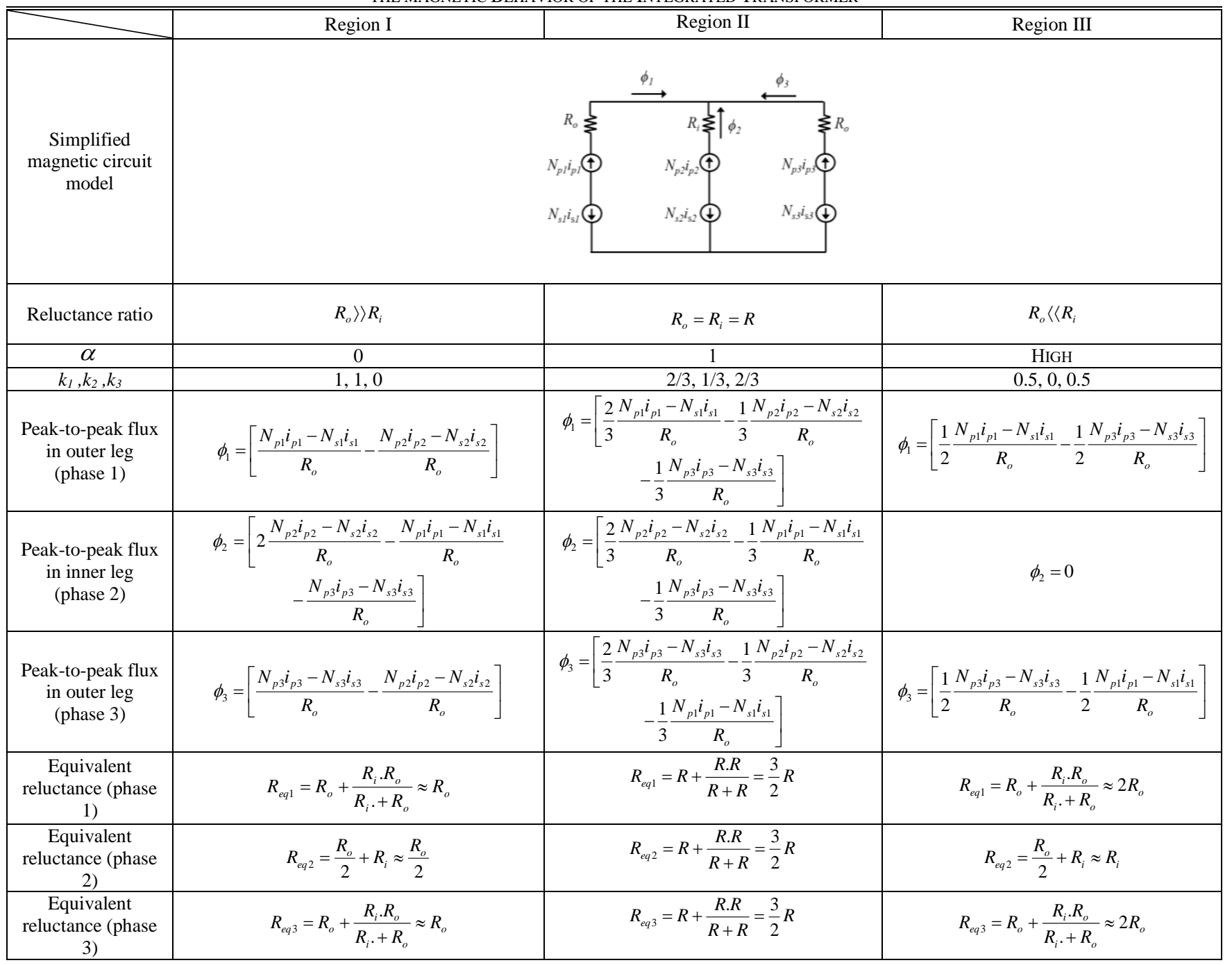


TABLE II

Design Example.

\begin{tabular}{|c|c|c|}
\hline Magnetic core topology & $\begin{array}{l}\text { Three-discrete Transformers } \\
\text { *Each phase consists of highly-coupled primary and secondary } \\
\text { windings. }\end{array}$ & $\begin{array}{l}\text { Integrated Transformer (Design based on Region 2) } \\
\text { *Each phase consists of highly-coupled primary and secondary } \\
\text { windings. }\end{array}$ \\
\hline A. Material selection & Ferrite, $\mathrm{Mn}-\mathrm{Zn}$ PC40 & Ferrite, Mn-Zn PC40 \\
\hline B. Area product & $A_{p}=1.55 \times 2.4=3.72 \mathrm{~cm}^{4}>2 \mathrm{~cm}^{4}$ & $A_{p}=6.4 \times 2.8=17.9 \mathrm{~cm}^{4}>1.38 \mathrm{~cm}^{4}$ \\
\hline C. Core selection & $3 \times(\mathrm{PC} 40 \mathrm{EER} 42 / 42 / 20-\mathrm{Z})$ & $1 \times(P C 40$ EC70x69×16) \\
\hline D. Transformer turns ratio & $N=\frac{N_{p}}{N_{s}}=\frac{V_{i} / 2}{V_{o}+V_{f}}=\frac{390 / 2}{12+0.82}=15.2 \approx 16$ & $N=\frac{N_{p}}{N_{s}}=\frac{V_{i} / 2}{V_{o}+V_{f}}=\frac{390 / 2}{12+0.82}=15.2 \approx 16$ \\
\hline $\begin{array}{l}\text { E. Effective permeability } \\
\qquad[\mathrm{H} / \mathrm{m}]\end{array}$ & $\mu_{e f f}=\frac{L_{m} M P L}{\mu_{o} N_{p}^{2} A}=\frac{\left(132 \times 10^{-6}\right)(0.099)}{\left(4 \pi \times 10^{-7}\right)(32)^{2}\left(2.4 \times 10^{-4}\right)}=42$ & $\mu_{e f f}=\frac{L_{m} M P L}{\mu_{o} N_{p}^{2} A}=\frac{\left(132 \times 10^{-6}\right)(0.144)}{\left(4 \pi \times 10^{-7}\right)(32)^{2}\left(2.8 \times 10^{-4}\right)}=53$ \\
\hline $\begin{array}{l}\text { F. Magnetic reluctance } \\
\text { and the air gap Length }\end{array}$ & $\begin{array}{l}R_{e q}=R_{c}+R_{g} \approx R_{g} \\
R_{e q}=\frac{M P L}{\mu_{r} \mu_{o} A_{c}}+\frac{l_{g}}{\mu_{o} A_{c}}=\frac{M P L}{\mu_{o} A_{c}}\left[\frac{1}{\mu_{r}}+\frac{l_{g}}{M P L}\right] \\
\mu_{e f f}=\frac{1}{\frac{1}{\mu_{r}}+\frac{l_{g}}{M P L}} \approx \frac{M P L}{l_{g}} \\
l_{g}=\frac{M P L}{\mu_{e f f}}=\frac{0.099}{42}=2.35 \mathrm{~mm} \\
R_{e q}=\frac{0.099}{4 \pi \times 10^{-7}\left(2.4 \times 10^{-4}\right)}\left[\frac{1}{2500}+\frac{2.35 \times 10^{-3}}{0.099}\right]=7757477 \mathrm{H}^{-1}\end{array}$ & $\begin{array}{l}R_{e q}=R_{c}+R_{g}+\frac{R_{g}}{2}=R_{c}+\frac{3}{2} R_{g} \approx \frac{3}{2} R_{g} \\
R_{e q}=\frac{M P L}{\mu_{r} \mu_{o} A_{c}}+\frac{3}{2} \frac{l_{g}}{\mu_{o} A_{c}}=\frac{M P L}{\mu_{o} A_{c}}\left[\frac{1}{\mu_{r}}+\frac{3}{2} \frac{l_{g}}{M P L}\right] \\
\mu_{e f f}=\frac{1}{\frac{1}{\mu_{r}}+\frac{3}{2} \frac{l_{g}}{M P L}} \approx \frac{2}{3} \frac{M P L}{l_{g}} \\
l_{g}=\frac{2}{3} \frac{M P L}{\mu_{e f f}}=\frac{2}{3} \frac{0.144}{53}=1.8 m m \\
R_{e q}=\frac{0.144}{4 \pi \times 10^{-7}\left(2.8 \times 10^{-4}\right)}\left[\frac{1}{2500}+\frac{3}{2} \frac{1.8 \times 10^{-3}}{0.144}\right]=7837244 H^{-1}\end{array}$ \\
\hline $\begin{array}{l}\text { G. Designed value of } \\
\text { Magnetizing inductance }\end{array}$ & $L_{m}=\frac{N^{2}}{R}=\frac{(32)^{2}}{7757477}=132 \mu H$ & $L_{m}=\frac{N^{2}}{R}=\frac{(32)^{2}}{7837244}=131 \mu \mathrm{H}$ \\
\hline $\begin{array}{l}\text { H. Flux density }\left(\mathrm{Bm}_{\mathrm{m}}\right) \\
\text { [based on the effective } \\
\text { cross section area of } \\
\text { the core] }\end{array}$ & $B_{m}=\frac{1}{2}\left[\frac{12 \times 0.465}{2 \times 225 \times 10^{3} \times 2.4 \times 10^{-4}}\right]=0.026 T$ & $\begin{array}{l}B_{m}=\frac{1}{2}\left[\frac{12 \times 0.445}{2 \times 165 \times 10^{3} \times 2.8 \times 10^{-4}}\right]=0.029 T \\
\text { The outer leg cross section area }=1.5 \mathrm{~cm}^{2} \text {, therefore the } \\
\text { maximum flux in the outer leg is } \\
B_{m_{-} \text {outer }}=\frac{1}{2}\left[\frac{12 \times 0.445}{2 \times 165 \times 10^{3} \times 1.5 \times 10^{-4}}\right]=0.054 T\end{array}$ \\
\hline I. Reluctance Factor $(\alpha)$ & Not applicable. & $\alpha=\frac{R_{i}}{R_{o}}=\frac{R_{g}}{R_{g}}=1$ \\
\hline
\end{tabular}

The primary switches operate with a fixed duty cycle $(d=0.5)$. It worth mentioning that the switching duty cycle shall be replaced by an effective duty cycle " $d_{e f f}$ " when it comes to relating the maximum flux density with the reflected secondary voltage and the secondary number of turns, in LLC converter working below resonance. The effective duty cycle equals the switching duty cycle $\left(d_{e f f}=d_{s}=0.5\right)$ when the converter operates at the normalized frequency $f_{n}=1$ (i.e the switching frequency $=$ resonance frequency), in which the secondary diodes are continuously conducting and the secondary voltage is clamped to the magnetizing inductance. Nonetheless, for operation below the resonant frequency, which is the case in this paper, the secondary devices stop conducting before the end of the switching half-cycle, therefore, the voltage across the magnetizing inductance is no longer clamped to the primary reflected output voltage.

The maximum flux density in each leg of the integrated transformer can be expressed as

$$
B_{m-1}=\frac{1}{2}\left[\frac{V_{o} \cdot d_{e f f}}{N_{s 1} \cdot f_{s} \cdot A_{o}}\right]
$$


TABLE III

MEASUREd VALUES OF THE THREE-Discrete TRANSFORMERS

\begin{tabular}{lccc}
\hline \hline Parameters & $\begin{array}{c}\text { Transfor- } \\
\text { mer No.1 }\end{array}$ & $\begin{array}{l}\text { Transfor- } \\
\text { mer No.2 }\end{array}$ & $\begin{array}{c}\text { Transfor- } \\
\text { mer No.3 }\end{array}$ \\
\hline Magnetic core & 3 cores & PC40 EER42/42/20-Z) \\
Open circuit test & $157 \mu \mathrm{H}$ & $146.8 \mu \mathrm{H}$ & $149.2 \mu \mathrm{H}$ \\
Resonance inductance $L_{r}$ & $20 \mu \mathrm{H}$ & $24.2 \mu \mathrm{H}$ & $21.5 \mu \mathrm{H}$ \\
Magnetizing inductance $L_{m}$ & $137 \mu \mathrm{H}$ & $122.6 \mu \mathrm{H}$ & $127.7 \mu \mathrm{H}$ \\
Number of Turns & $32: 2: 2$ & $32: 2: 2$ & $32: 2: 2$ \\
\hline \hline
\end{tabular}

TABLE IV

MEASURED VALUES OF THE INTEGRATED TRANSFORMER

\begin{tabular}{lccc}
\hline \hline \multirow{2}{*}{ Parameters } & Phase & Phase & Phase \\
& No.1 & No.2 & No.3 \\
\hline Magnetic core & \multicolumn{2}{c}{1 core $($ PC40 EC70x69x16) } \\
Open circuit test & $160.3 \mu \mathrm{H}$ & $158.4 \mu \mathrm{H}$ & $156.7 \mu \mathrm{H}$ \\
Resonance inductance $L_{r}$ & $34.5 \mu \mathrm{H}$ & $34 \mu \mathrm{H}$ & $35.3 \mu \mathrm{H}$ \\
Magnetizing inductance $L_{m}$ & $125.8 \mu \mathrm{H}$ & $124.4 \mu \mathrm{H}$ & $121.4 \mu \mathrm{H}$ \\
Number of Turns & $32: 2: 2$ & $32: 2: 2$ & $32: 2: 2$ \\
\hline \hline
\end{tabular}

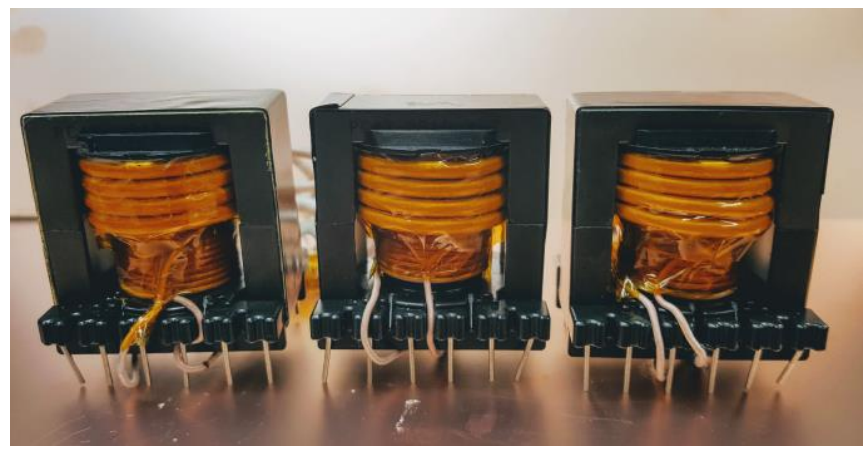

(a)

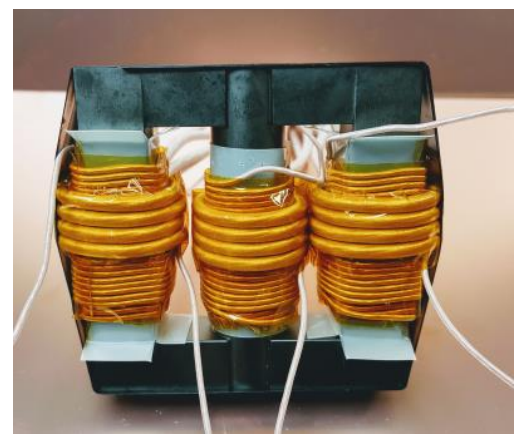

(b)

Fig. 9. The three discrete transformers and the integrated transformer.

$$
\begin{aligned}
& B_{m-2}=\frac{1}{2}\left[\frac{V_{o} \cdot d_{e f f}}{N_{s 2} \cdot f_{s} \cdot A_{i}}\right] \\
& B_{m-3}=\frac{1}{2}\left[\frac{V_{o} \cdot d_{e f f}}{N_{s 3} \cdot f_{s} \cdot A_{o}}\right]
\end{aligned}
$$

Where $A_{o}, A_{i}$ and $d_{\text {eff }}$ are the cross section area of the outer leg, inner leg of the magnetic core and the effective duty cycle, respectively. The derivation of the effective duty cycle can be obtained as follows:

When the LLC converter operates below resonance, each half of the switching cycle contains a power delivery operation, at
TABLE V

DESIGN SPECIFICATIONS FOR THE LLC RESONANT CONVERTER WITH INTEGRATED TRANSFORMER

\begin{tabular}{llc}
\hline \hline Symbol & Quantity & Value \\
\hline$P_{o}$ & Output power & $500 \mathrm{~W}$ \\
$V_{i}$ & Input voltage & $390 \mathrm{~V}$ \\
$V_{o}$ & Output voltage & $12 \mathrm{~V}$ \\
$f_{s}$ & Switching frequency range & $165 \mathrm{kHz}-230 \mathrm{kHz}$ \\
$C_{r}, C_{r 2}, C_{r 3}$ & Resonant capacitance & $22 n \mathrm{~F}$ \\
$N$ & Turns ratio & 16 \\
\hline \hline
\end{tabular}

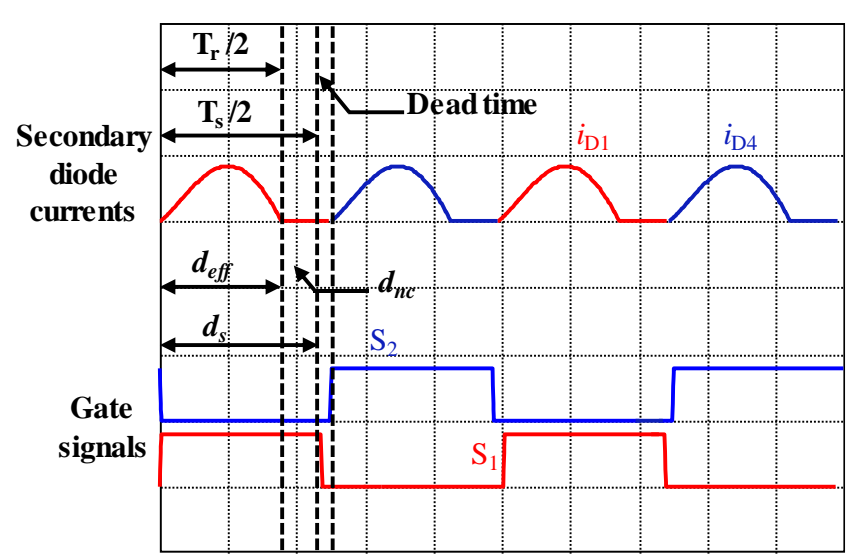

Fig.7 Secondary rectified current waveforms for one phase.

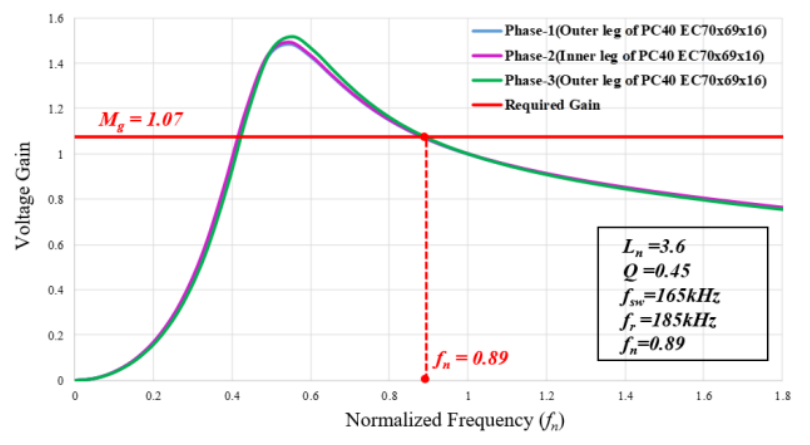

Fig.8 Voltage gain curve of three-phase LLC with integrated transformer.

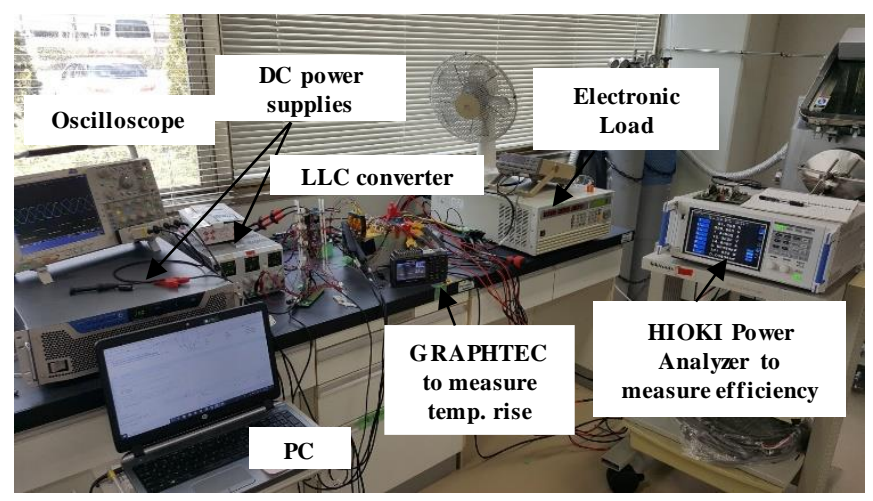

Fig.10 Experimental environment.

which the magnetizing current is lower than the resonant current, this period can be estimated as $\left(T_{r} / 2\right)$, as shown in Fig.7. As the resonant current equals the magnetizing current the secondary diodes stop to conduct, and the primary reflected 
secondary voltage is no longer clamped to the magnetizing inductance. The effective duty cycle can be expressed as

$$
d_{e f f}=d_{s}-d_{n c}
$$

Where $d_{e f f}, d_{s}$, and $d_{n c}$ are the effective duty cycle, the switching duty cycle $\left(d_{s}=0.5\right)$, and the duty cycle at which there is no conduction through the secondary rectifiers.

The time where there is no conduction through the secondary rectifiers for each half-cycle can be determined as

$$
T_{n c}=\frac{T_{s}}{2}-\frac{T_{r}}{2}=\frac{1}{2}\left(\frac{1}{f_{s}}-\frac{1}{f_{r}}\right)
$$

The duty cycle $d_{n c}$ can be denoted as

$$
d_{n c}=d_{s} \frac{\frac{1}{2}\left(\frac{1}{f_{s}}-\frac{1}{f_{r}}\right)}{\frac{1}{2 f_{s}}}
$$

The duty cycle in which there is no conduction through the secondary rectifiers can be further simplified as

$$
d_{n c}=d_{s}\left(1-\frac{f_{s}}{f_{r}}\right)
$$

The effective duty cycle can be expressed by substituting (25) in (22) as

$$
d_{\text {eff }}=d_{s}-d_{s}\left(1-\frac{f_{s}}{f_{r}}\right)
$$

Equation (26) can be further simplified as

$$
d_{e f f}=\frac{f_{s}}{2 f_{r}}=\frac{f_{n}}{2}
$$

It is noticeable that when the when the primary switches are driven with a frequency equals to the resonance $\left(f_{n}=1\right)$, the duty cycle $d_{n c}=0$. In this case, the effective duty cycle equals the switching duty cycle $\left(d_{e f f}=d_{s}=0.5\right)$.

\section{DESIGN EXAMPLE}

The integrated transformer is intended to be utilized in a 500W three-phase LLC resonant converter. This LLC converter is $390 \mathrm{~V} / 12 \mathrm{~V}$ step down converter. The specifications of this converter are tabulated in table V. The desired gain is shown in Fig.8 and calculated as follows.

$$
M_{g}=\frac{N_{p}}{N_{s}} \frac{\left(V_{o}+V_{f}\right)}{\left(V_{i} / 2\right)}=16 \frac{(12+1.08)}{(390 / 2)}=1.07
$$

Where $V_{i}, V_{o}$, and $V_{f}$ are the input voltage, output voltage, and secondary diode voltage drop; respectively. The gain curve of the three-phase LLC converter had been calculated and drawn in this discussion based on the derivation of FHA circuit presented in [18]. In LLC resonant converter the gapped transformer operates with high frequency current variation, resulting large B-H loop and high core losses. Therefore, the maximum flux density must be limited by the core losses rather than the saturation. Ferrite material is suitable for such application, and Mn-Zn PC40 with a situation flux density of $0.38 \mathrm{~T}$ has been selected for that purpose.

The magnetic core has selected based on the area product. Area product is defined as the product of core window area $W_{a}$ and cross section area $A_{c}$. The area product can be interpreted as an indication of how the selected core can handle the magnetic energy with a permissible temperature rise, and it can be calculated in a unit of $\left[\mathrm{cm}^{4}\right]$ as follows [34]

$$
A_{p}=\left[\frac{\sqrt{k_{u}} L_{m} I_{m_{-} \max } I_{r_{-} r m s}}{B_{\max } k_{u} K_{t} \sqrt{\Delta T}}\right]^{\frac{8}{7}} x 10^{8}
$$

The window utilization factor, $\mathrm{K}_{\mathrm{u}}$, is defined as the ratio of the total conduction area $\mathrm{W}_{\mathrm{c}}$, for all conductors to the total window area $\mathrm{W}_{\mathrm{a}} .\left(\mathrm{K}_{\mathrm{u}}=\mathrm{W}_{\mathrm{c}} / \mathrm{W}_{\mathrm{a}}\right)$.

The window area $\mathrm{W}_{\mathrm{a}}$ of PC40 EC70x69x16 is $=6.4 \mathrm{~cm}^{2}$ and the total area of the primary windings is $0.628 \times 32=20 \mathrm{~mm}^{2}=0.2 \mathrm{~cm}^{2}$ and the secondary winding is $3.8 \times 4=15.2 \mathrm{~mm}^{2}=0.15 \mathrm{~cm}^{2}$. However, within the integrated transformer one window is shared between two phases, therefore the winding utilization factor $\mathrm{K}_{\mathrm{u}}=(2 \times 0.2+2 \times 0.15) / 6.4=0.1$. In case of the three discrete transformers, $\mathrm{K}_{\mathrm{u}}=(0.2+0.15) / 1.55=0.22$. A lower value of window utilization factor improves the thermal performance of the integrated transformer, as shown in the thermal evaluation results in section IV. C.

Maximum flux density in the outer leg is calculated in Table. II as $0.054 \mathrm{~T}$ for the integrated transformer. $\mathrm{K}_{\mathrm{t}}$ is a constant and equals $48.2 \times 10^{3}$. Therefore, the area product equals

$$
A_{p}=\left[\frac{(\sqrt{0.1})\left(132 \times 10^{-6}\right)(1.82)(2.5)}{(0.054)(0.1)\left(48.2 \times 10^{3}\right) \sqrt{30}}\right]^{\frac{8}{7}} \times 10^{8}=1.38 \mathrm{~cm}^{4}
$$

In case of the three discrete transformers

$$
A_{p}=\left[\frac{(\sqrt{0.22})\left(132 \times 10^{-6}\right)(1.82)(2.5)}{(0.026)(0.22)\left(48.2 \times 10^{3}\right) \sqrt{30}}\right]^{\frac{8}{7}} \times 10^{8}=2 \mathrm{~cm}^{4}
$$

The area product calculation helps us to evaluate the magnetic energy handling capability of the two transformer prototypes. In other words, the core which has higher area product value indicates that it can handle the same magnetic energy with less temperature rise, than a core with lower area product value [34][35]. In this context, the window area and the cross-section area of PC40 EC70x69x16 are $\mathrm{W}_{\mathrm{a}}=6.4 \mathrm{~cm}^{2}$ and $\mathrm{A}_{\mathrm{c}}=2.8 \mathrm{~cm}^{2}$, respectively, leading to an area product of $A_{p}=17.9 \mathrm{~cm}^{4}$. Whereas, the window area and the cross-section area of PC40 EER42/42/20-Z are $\mathrm{W}_{\mathrm{a}}=1.55 \mathrm{~cm}^{2}$ and $\mathrm{A}_{\mathrm{c}}=2.4 \mathrm{~cm}^{2}$, respectively, yield to an area product of $A_{p}=3.72 \mathrm{~cm}^{4}$ for the three discrete cores. Therefore, both cores are suitable. However, it worth mentioning that, as the area product of the integrated transformer is much bigger, it has a better thermal performance compared with the three-discrete transformer, as shown later in section IV D. 

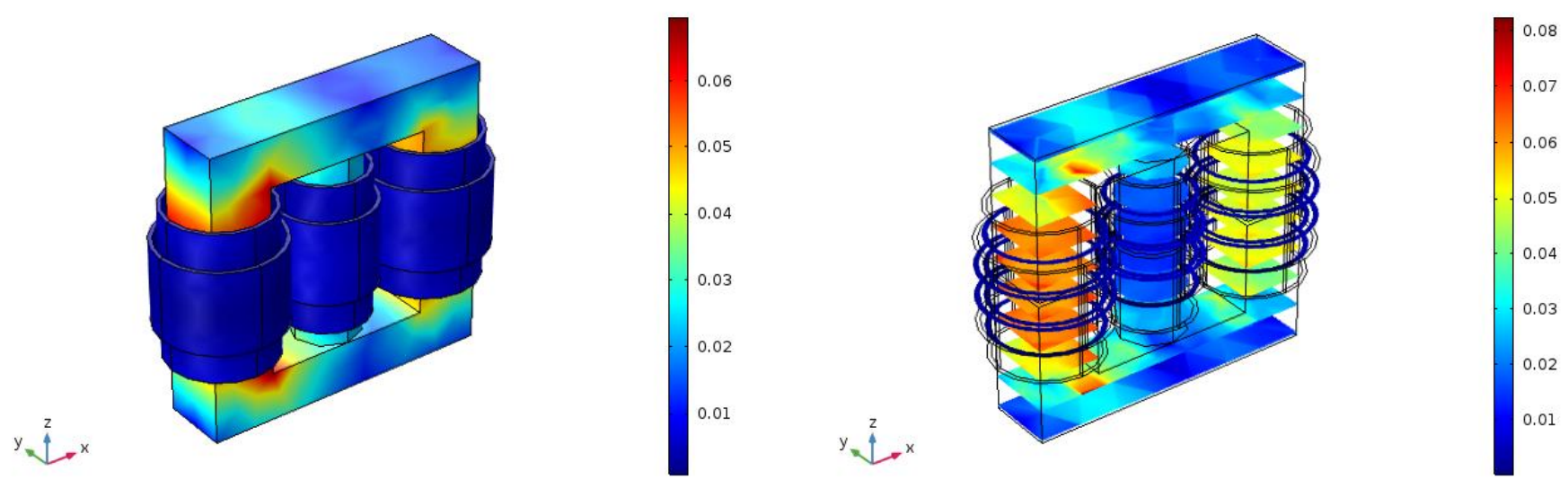

Fig.11 FEA simulations of the proposed integrated transformer.

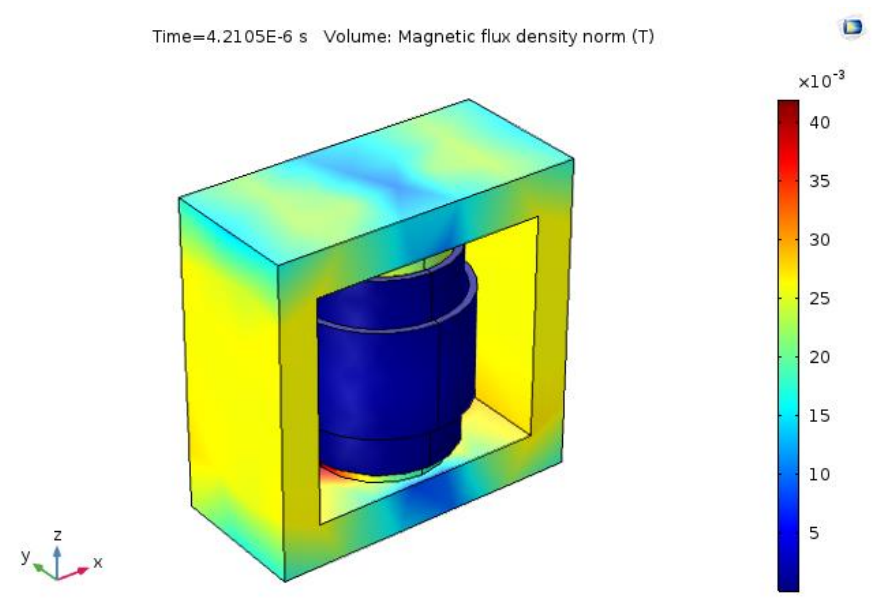

$\square$

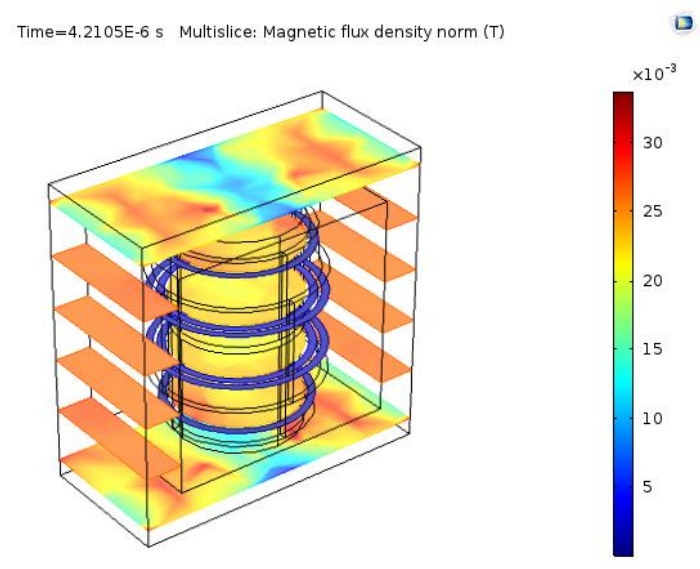

Fig.12 FEA simulations of single transformer out of the three discerte transformers.

The primary number of turns are calculated to be 32 turns, and the secondary number of turns are calculated to be 2 turns. The effective permeability is calculated to equal $53 \mathrm{H} / \mathrm{m}$. Litz wires have been utilized, and their cross-section area is $0.628 \mathrm{~mm}^{2}$, $3.8 \mathrm{~mm}^{2}$ for the primary and secondary windings, respectively.

In order to achieve a soft switching operation for the LLC converter, the effective permeability of the magnetic core shall be intentionally minimized. Therefore, the magnetic core transfers the power to the secondary side, and store energy in the air gap to discharge the steady state output capacitance of the primary switches during the dead time [36].

Reducing the value of effective permeability can be realized by inserting air gap in the Ferrite core. The parameters of the two prototypes are calculated and depicted in Table II. The magnetic cores of the three-discrete transformers and the integrated transformer are shown in Fig.9. The experimental setup is shown in Fig. 10.

\section{Simulation Tests, EXPERIMENTAL EVALUATION AND POWER LOSSES DISTRIBUTION}

\section{A. FEA Simulation}

This subsection presents the Finite Element Analysis (FEA) for the proposed EC70 integrated transformer, alongside with the EER42 core utilized for the three discrete transformers.

The simulation parameters are listed in Tables III and IV. The electromagnetic simulation was carried out using COSMOL Multiphysics software. The simulation results for the integrated transformer is shown in Fig.11, this figure was captured at fraction of second where phase- 3 has it is maximum value of flux density, while the flux density in the other two phases have lower value. The simulation for a single transformer out of the three units is depicted in Fig.12 (b).

Low magnetic flux density can be observed from the simulation 
results, since there is no dc biased magnetization, and the transformers operate with purely high frequency ac currents. The magnetic flux density values are consistent with the theoretical calculation of the design example shown in Table II.

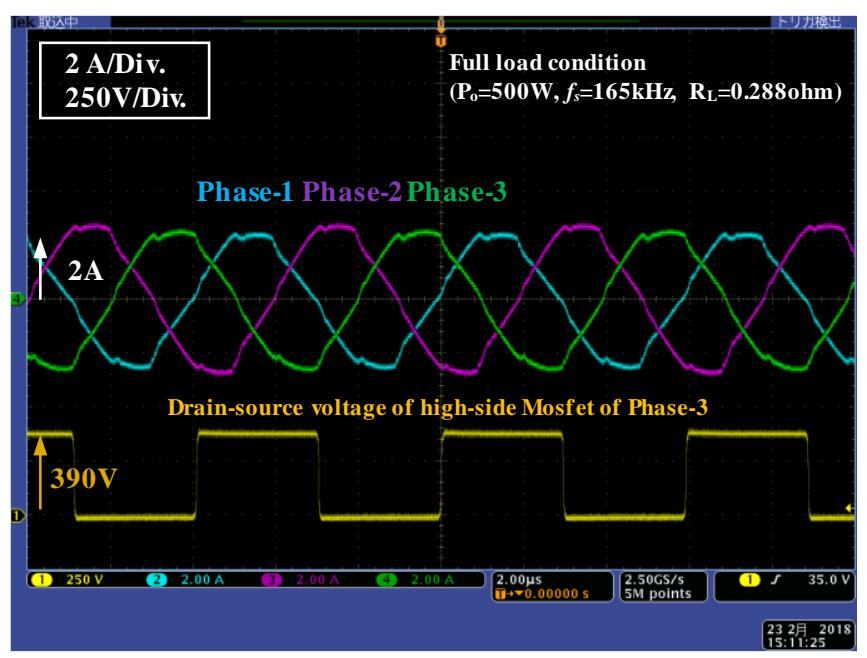

(a)

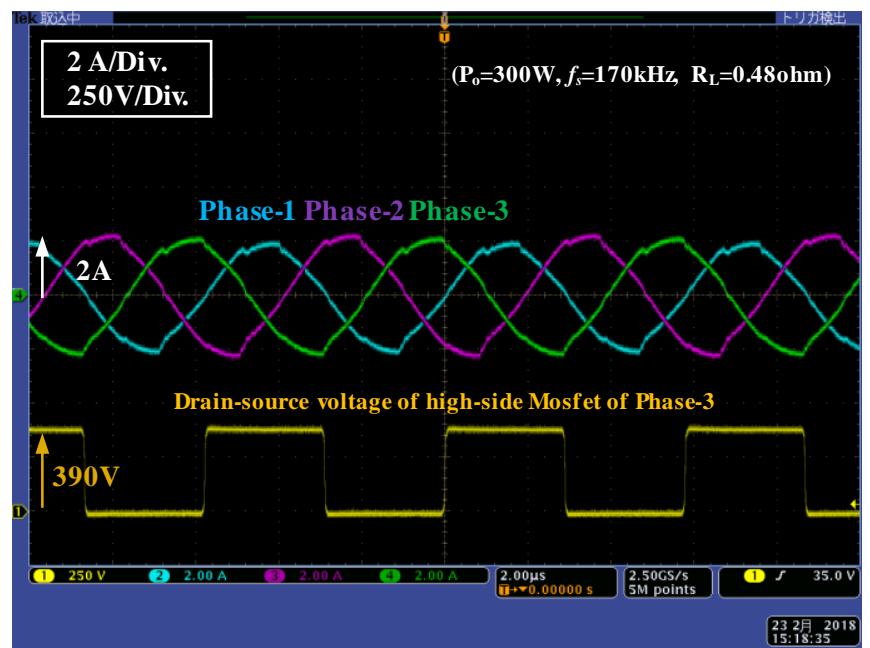

(b)

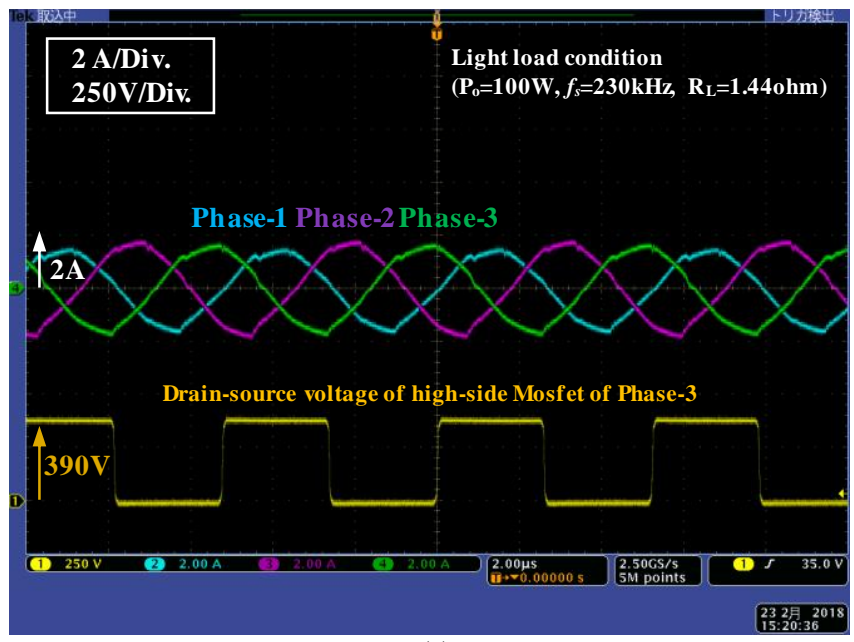

(c)

Fig.13 The resonant current waveforms for the integrated transformer. (a) full load condition $500 \mathrm{~W}$. (b) $300 \mathrm{~W}$ condition. (c) $100 \mathrm{~W}$ output power.

\section{B. Experimental Environment and Results}

In order to evaluate the proper operation of the three-phase LLC resonant converter with the three-legged integrated transformer, the converter was constructed and experimentally tested. The LLC prototype uses Schottky diodes (VS-100BGQ100), primary Mosfets (Toshiba, TK20E60W). Texas Instruments DSP is used to drive the primary switches. The three-legged integrated transformer can be implemented with different magnetic core structures, in this discussion we utilized ferrite core, PC40 EC70x69x16. The measured parameters of the three discrete transformers are listed in Table III, where three magnetic cores of PC40EER42/42/20-Z are utilized. The measured parameters of the integrated transformer are listed in Table IV.

The experimental results are shown in this section to show the proper operation of the power converter. Fig.13 (a) shows the resonant current with and drain-source voltage, where the integrated transformer is utilized and the converter operates at full load condition (i.e $P_{o}=500 W, V_{o}=12 V, I_{o}=41.67$, and $f_{s}$ $=165 \mathrm{kHz}$ ). In Fig.13 (b) shows the waveforms during $\left(\mathrm{P}_{\mathrm{o}}=300 \mathrm{~W}, \mathrm{~V}_{\mathrm{o}}=12 \mathrm{~V}, \mathrm{I}_{\mathrm{o}}=25\right.$, and $\left.\mathrm{f}_{\mathrm{s}}=170 \mathrm{kHz}\right)$. The light load condition is presented in Fig. 13 (c) where $\left(\mathrm{P}_{\mathrm{o}}=100 \mathrm{~W}, \mathrm{~V}_{\mathrm{o}}=12 \mathrm{~V}\right.$,

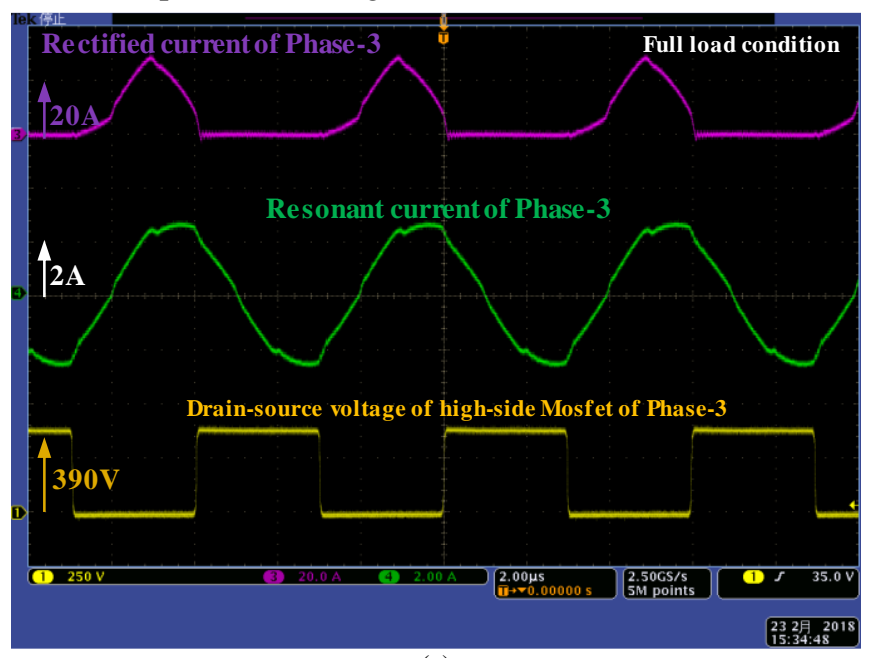

(a)

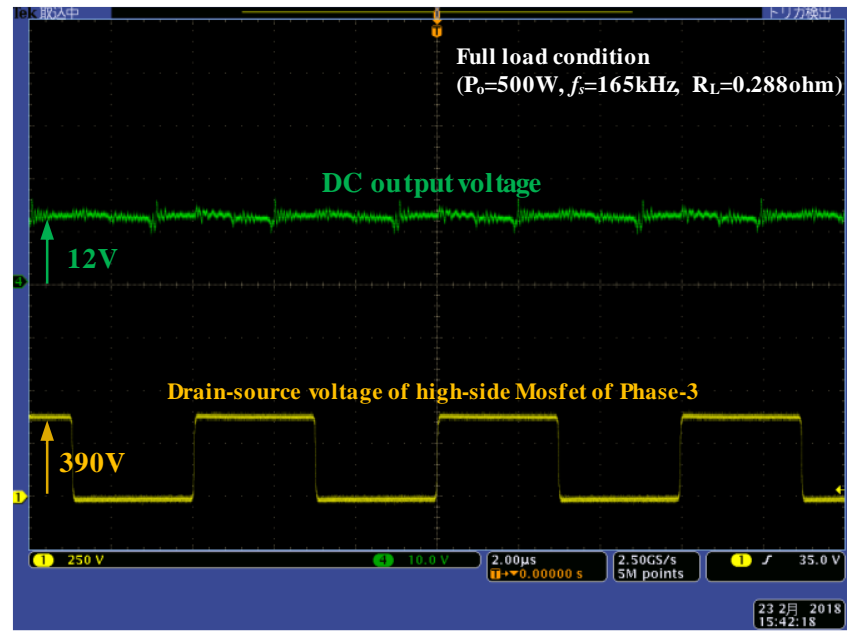

(b)

Fig. 14. Experimental waveforms. (a) Phase-3 resonant and rectifier current with the drain-source voltage of the high-side. (b) dc output voltage. 
TABLE VI

Efficiency measurements for the LLC resonant converter utilizing single PC40 EC70x69x16 integrated transformer

\begin{tabular}{|c|c|c|c|c|c|c|c|c|c|}
\hline & \multicolumn{9}{|c|}{ Inductor average current $6 \mathrm{~A}$} \\
\hline & $\begin{array}{l}\text { Input } \\
\text { Power }\end{array}$ & $\begin{array}{c}\text { Input } \\
\text { Voltage }\end{array}$ & $\begin{array}{l}\text { Input } \\
\text { current }\end{array}$ & $\begin{array}{l}\text { Switching } \\
\text { Frequency }\end{array}$ & $\begin{array}{l}\text { Output } \\
\text { Power }\end{array}$ & $\begin{array}{l}\text { Output } \\
\text { Voltage }\end{array}$ & $\begin{array}{l}\text { Output } \\
\text { current }\end{array}$ & $\begin{array}{l}\text { Power } \\
\text { Losses }\end{array}$ & Efficiency \\
\hline $\mathrm{P}_{\mathrm{o}}=500 \mathrm{~W}$ & $550.8 \mathrm{~W}$ & $390 \mathrm{~V}$ & $1.41 \mathrm{~A}$ & $165 \mathrm{kHz}$ & $500 \mathrm{~W}$ & $12.01 \mathrm{~V}$ & $41.67 \mathrm{~A}$ & $49.8 \mathrm{~W}$ & $90.95 \%$ \\
\hline $\mathrm{P}_{\mathrm{o}}=400 \mathrm{~W}$ & $442.8 \mathrm{~W}$ & $390 \mathrm{~V}$ & $1.14 \mathrm{~A}$ & $167 \mathrm{kHz}$ & $400 \mathrm{~W}$ & $12.07 \mathrm{~V}$ & $33.33 \mathrm{~A}$ & $40.1 \mathrm{~W}$ & $91 \%$ \\
\hline $\mathrm{P}_{\mathrm{o}}=300 \mathrm{~W}$ & $334.8 \mathrm{~W}$ & $390 \mathrm{~V}$ & $0.86 \mathrm{~A}$ & $170 \mathrm{kHz}$ & $300 \mathrm{~W}$ & $12.1 \mathrm{~V}$ & $25 \mathrm{~A}$ & $33.5 \mathrm{~W}$ & $90.8 \%$ \\
\hline$P_{o}=200 W$ & $219.5 \mathrm{~W}$ & $390 \mathrm{~V}$ & $0.56 \mathrm{~A}$ & $187 \mathrm{kHz}$ & $200 \mathrm{~W}$ & $11.95 \mathrm{~V}$ & $16.67 \mathrm{~A}$ & $20.9 \mathrm{~W}$ & $90.5 \%$ \\
\hline $\mathrm{P}_{\mathrm{o}}=100 \mathrm{~W}$ & $111.4 \mathrm{~W}$ & $390 \mathrm{~V}$ & $0.285 \mathrm{~A}$ & $230 \mathrm{kHz}$ & $100 \mathrm{~W}$ & $11.9 \mathrm{~V}$ & $8.3 \mathrm{~A}$ & $12.7 \mathrm{~W}$ & $88.6 \%$ \\
\hline
\end{tabular}

TABLE VII

Efficiency measurements for the LLC resonant converter utilizing three PC40EER42/42/20-Z transformers

\begin{tabular}{|c|c|c|c|c|c|c|c|c|c|}
\hline & \multicolumn{9}{|c|}{ Inductor average current $6 \mathrm{~A}$} \\
\hline & $\begin{array}{l}\text { Input } \\
\text { Power }\end{array}$ & $\begin{array}{c}\text { Input } \\
\text { Voltage }\end{array}$ & $\begin{array}{c}\text { Input } \\
\text { current }\end{array}$ & $\begin{array}{l}\text { Switching } \\
\text { Frequency }\end{array}$ & $\begin{array}{l}\text { Output } \\
\text { Power }\end{array}$ & $\begin{array}{l}\text { Output } \\
\text { Voltage }\end{array}$ & $\begin{array}{l}\text { Output } \\
\text { current }\end{array}$ & $\begin{array}{l}\text { Power } \\
\text { Losses }\end{array}$ & Efficiency \\
\hline $\mathrm{P}_{\mathrm{o}}=500 \mathrm{~W}$ & $568 \mathrm{~W}$ & $390 \mathrm{~V}$ & $1.46 \mathrm{~A}$ & $225 \mathrm{kHz}$ & $500 \mathrm{~W}$ & $12.1 \mathrm{~V}$ & $41.67 \mathrm{~A}$ & $59.4 \mathrm{~W}$ & $89.7 \%$ \\
\hline $\mathrm{P}_{\mathrm{o}}=400 \mathrm{~W}$ & $452 \mathrm{~W}$ & $390 \mathrm{~V}$ & $1.15 \mathrm{~A}$ & $236 \mathrm{kHz}$ & $400 \mathrm{~W}$ & $12.1 \mathrm{~V}$ & $33.33 \mathrm{~A}$ & $44.7 \mathrm{~W}$ & $90.1 \%$ \\
\hline $\mathrm{P}_{\mathrm{o}}=300 \mathrm{~W}$ & $340.9 \mathrm{~W}$ & $390 \mathrm{~V}$ & $0.87 \mathrm{~A}$ & $246 \mathrm{kHz}$ & $300 \mathrm{~W}$ & $12.1 \mathrm{~V}$ & $25 \mathrm{~A}$ & $33.3 \mathrm{~W}$ & $90.2 \%$ \\
\hline $\mathrm{P}_{\mathrm{o}}=200 \mathrm{~W}$ & $224.9 \mathrm{~W}$ & $390 \mathrm{~V}$ & $0.58 \mathrm{~A}$ & $275 \mathrm{kHz}$ & $200 \mathrm{~W}$ & $12.1 \mathrm{~V}$ & $16.67 \mathrm{~A}$ & $23.2 \mathrm{~W}$ & $89.7 \%$ \\
\hline $\mathrm{P}_{\mathrm{o}}=100 \mathrm{~W}$ & $114 \mathrm{~W}$ & $390 \mathrm{~V}$ & $0.29 \mathrm{~A}$ & $335 \mathrm{kHz}$ & $100 \mathrm{~W}$ & $12 \mathrm{~V}$ & $8.3 \mathrm{~A}$ & $14 \mathrm{~W}$ & $87.67 \%$ \\
\hline
\end{tabular}

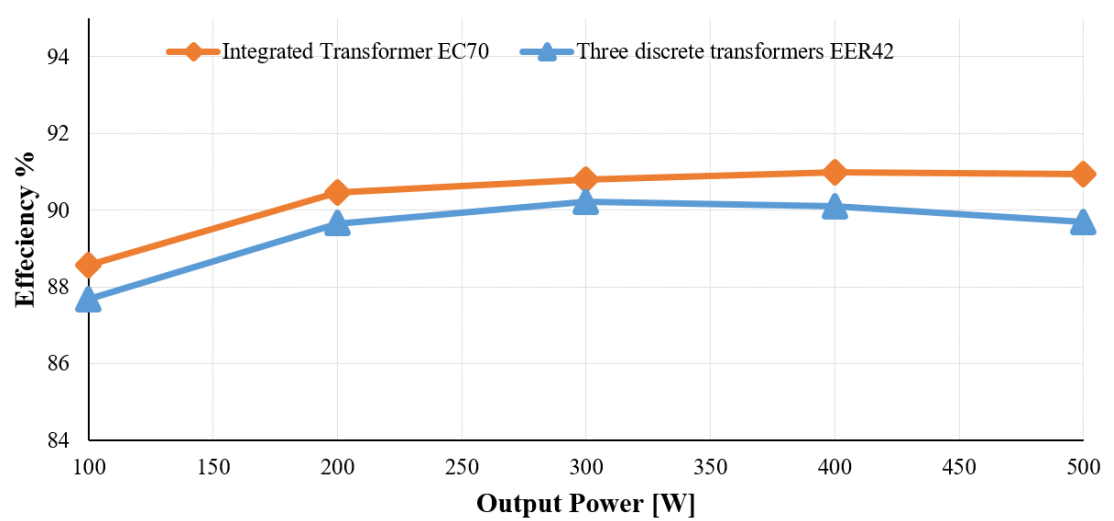

Fig. 15 Efficiency measurements for the integrated transformers and the three-discrete transformers.

$\mathrm{I}_{\mathrm{o}}=8.3$, and $\mathrm{f}_{\mathrm{s}}=230 \mathrm{kHz}$ ). Fig. 14 (a) shows the rectified current, resonant current, drain-source voltage of on phase-3. The $d c$ output voltage is shown in Fig.14 (b). The integrated transformer is connected into star connection helps to suppress the current unbalance which arises from the uneven resonant tank parameters.

It worth mentioning that the resonant current waveform becomes pure sinusoidal only when the frequency of resonant tank equals the switching frequency (i.e $f_{n}=1$ ). However, usually the LLC converter operates in the below resonance region to realize soft switching operation. A feature of the operating below resonance is that the resonant current reaches the value of the magnetizing current before the end of the halfcycle. Therefore, the magnetizing current imposes some distortion to the pure sinusoidal waveform, as in this discussion $f_{n}=0.89$ at full load condition.

\section{Efficiency}

In this section, the efficiency measurements are presented for both the integrated transformer and the three-discrete transformers. The efficiency evaluation had been conducted using HIOKI PW6001 Power Analyzer. The efficiency tests were conducted at several power output levels, in particular: $100 \mathrm{~W}, 200 \mathrm{~W}, 300 \mathrm{~W}, 400 \mathrm{~W}$, and 500W. The input voltage was fixed at $390 \mathrm{~V}$ and output voltage at $12 \mathrm{~V}$. The measurements are tabulated in Tables VI and VII. The maximum efficiency of the LLC utilizing the integrated transformer is $91 \%$, while the three-discrete transformers could achieve a maximum efficiency of $90.1 \%$, as shown in Fig. 15.

The core loss of the integrated transformer is disclosed in section IV.F to be lower than the sum of the core loss in three discrete transformers. However, as the transformer maximum flux density is relatively low in this LLC converter, the core loss contribution into the total converter loss can be considered small, in both prototypes. The major power loss is originated in the secondary rectifiers due to the high value of output current. Furthermore, the three discrete transformers prototype has a higher copper loss in the transformer windings, because the windings has higher ac resistance, as the switching frequency of the three transformers prototype is higher than the integrated transformer's prototype. The power loss breakdown is presented in more details in section IV.F.

\section{Thermal Performance}

An important aspect to consider while evaluating the integrated transformer is to evaluate its thermal performance. The core temperature rise was tested experimentally using Graphtec, midi logger GL240. No external fans have been used while conducting this thermal measurement test. 


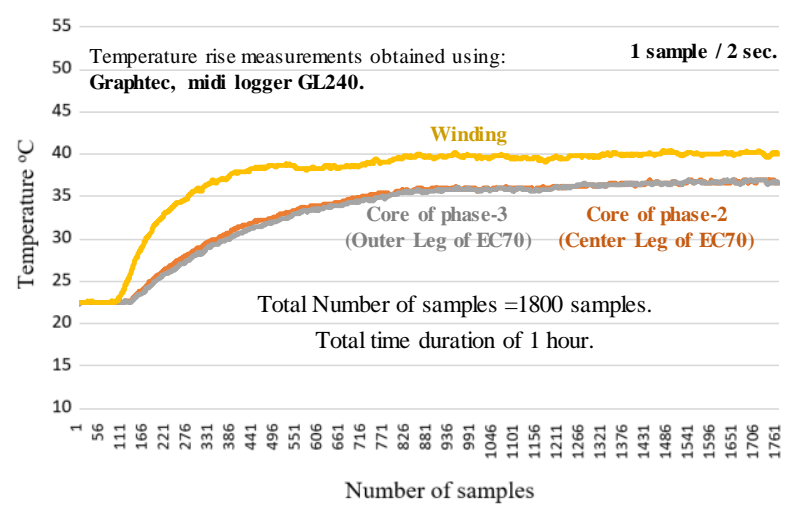

Fig.16 Temperature rise of integrated transformer.

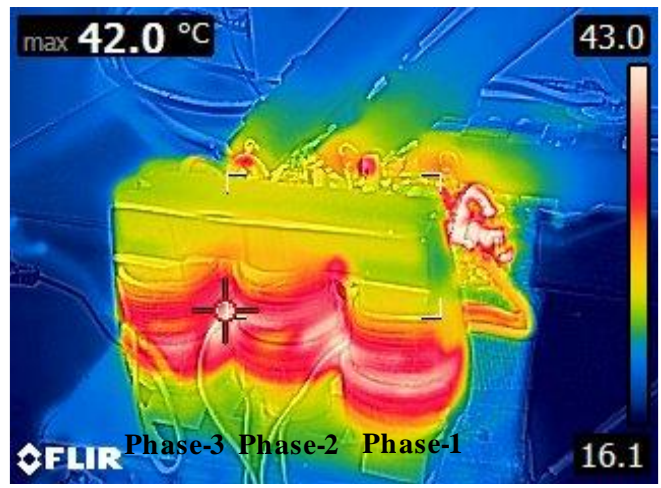

Fig.18 Thermal image of the integrated transformer.

The first three minutes are left without operating the converter to measure the ambient temperature of our power electronics laboratory. Then the temperature rise test lasts for 1 hour. The device was set to capture 1 sample each 2 seconds. Therefore, the total number of samples is 1800 samples. The temperature rise of the integrated transformer is depicted in Fig.16, and for the three-transformers the temperature rise is shown in Fig.17. Furthermore, we used FLIR thermal imaging camera to capture the thermal image of the both transformer configurations. The thermal image of the integrated transformer is depicted in Fig.18, and for the three-discrete transformers are shown in Fig.19. In case of the integrated transformer, the maximum winding temperature is around $40^{\circ} \mathrm{C}$ and the core temperature saturates at around $37^{\circ} \mathrm{C}$.

It worth mentioning that as the three-phases share the same magnetic core, therefore a uniform temperature distribution along the core had been realized. As shown in Fig.16, the temperature of both the center leg and outer leg is almost identical. On the other hand, in case of the three-discrete transformers, each phase temperature deviates a little from the other ones.

It can be deduced from that the integrated transformer has a better thermal performance than the discrete transformers, it is because a transformer temperature rise depends upon the core external thermal resistance $\mathrm{R}_{\mathrm{ET}}\left({ }^{\circ} \mathrm{C} / \mathrm{Watt}\right)$. The external thermal resistance can be estimated as a function of the core window area, using a simple formula based on rule of thumb [37], during an average situation of natural convection cooling, as follows

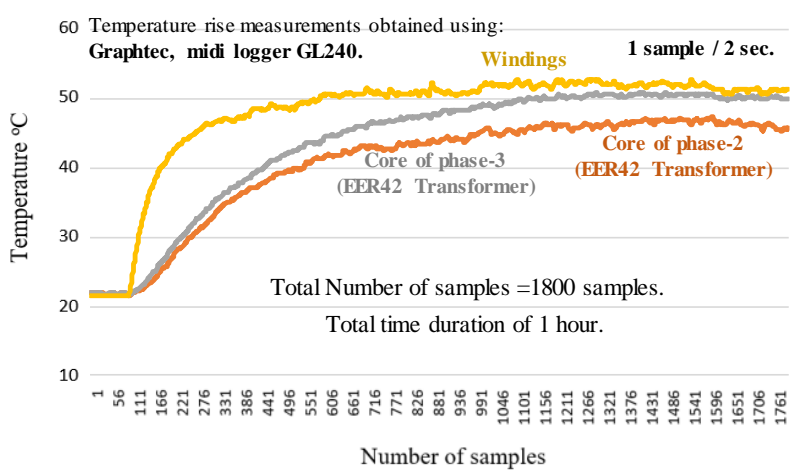

Fig.17 Temperature rise of integrated transformer.

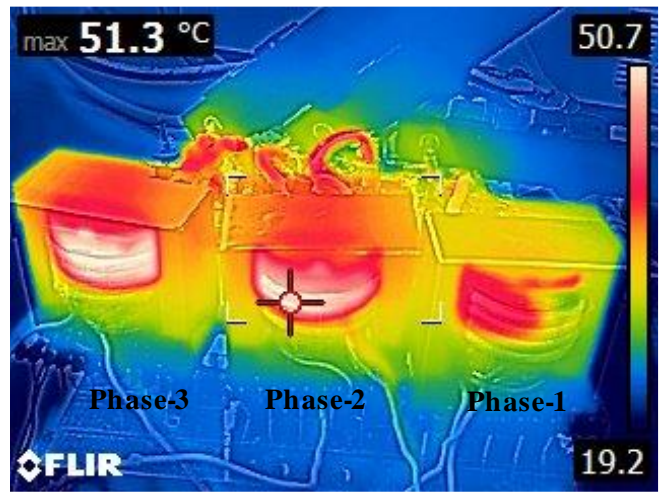

Fig.19 Thermal image of the three discrete transformers.

$R_{E T}=\frac{36}{W_{a}\left[\mathrm{~cm}^{2}\right]}{ }^{\circ} \mathrm{C} / \mathrm{Watt}$

The integrated transformer has a higher value of window area $\left(W_{a}=6.4 \mathrm{~cm}^{2}\right)$, than the window area of the discrete transformers $\left(W_{a}=1.55 \mathrm{~cm}^{2}\right)$. Therefore, and based on (32), it can be deduced that the integrated transformer has a lower external thermal resistance compared to the discrete transformers.

\section{E. Volume, weight and Cost Comparison between integrated and discrete transformers}

In this section, the merits of employing the integrated transformer from practical point of view are reported. The discussion includes a comparison between the three integrated transformer and the three-discrete transformers on the basis of volume, weight and cost as follow: Referring to the product catalog of TDK [38], the magnetic core's volume and weight of the integrated transformer are $40.42 \mathrm{~cm}^{3}$ and $250 \mathrm{~g}$. Referring to [39], the total volume and weight of the discrete transformers are $3 \times 23.7=71.1 \mathrm{~cm}^{3}$ and $3 \times 116=348 \mathrm{~g}$. In other words, for the same LLC resonant converter, the integrated transformer enables an approximate $43 \%$ transformer volume reduction as compared with the three discrete transformer, and a weight reduction of $28 \%$. Moreover, the dead spaces between the discrete transformers are no longer required in case of utilizing the integrated transformer. From the website of Allied Electronics [40], the estimated cost of magnetic core for the integrated transformer is $7.06 \mathrm{USD} /$ unit. However, the total cost for the three discrete magnetic cores is $3 \times 2.8=8.4 \mathrm{USD} / \mathrm{unit}$. The windings cost is out of comparison. Therefore, employing 
the magnetic integrated transformer would achieve a cost reduction of $16 \%$.

\section{F. Power loss distribution}

In this section, the loss breakdown of the three-phase LLC resonant converter is presented with the two transformer topologies. The power loss in the three-discrete transformers topology can be calculated as follow

(i) Conduction loss of primary switches:

$$
P_{\text {con }}=I_{r-r m s} R_{d s-o n}
$$

The MOSFETs utilized in our prototype are Toshiba, TK20E60W, with a drain-source resistance of $0.13 \Omega$. The effective current value through the switches is $1.66 \mathrm{~A}$. The total conduction loss of the MOSFETs $=6 \times 0.13 \times(1.66)^{2}=$ $2.15 \mathrm{~W}$.

(ii) Conduction loss of secondary rectifiers:

$P_{\text {diode }}=V_{F} \cdot I_{D-r m s}$

The secondary rectifiers are Schottky diodes VS100BGQ100 with a $V_{f}=0.6$ at $6.9 \mathrm{~A}$ rms value of the halfwave secondary current, leading to a total conduction loss of $=6 \times 0.6 \times 6.95=25 \mathrm{~W}$.

(iii) The copper loss of the transformer

$$
P_{c o p p-T}=I_{p r i-r m s}^{2} R_{p r i-a c}+I_{\mathrm{sec}-r m s}^{2} R_{\mathrm{sec}-a c}
$$

The $a c$ resistance of the transformers primary winding was measured as $2.93 \Omega$ and for the secondary winding is $0.37 \Omega$, leading to a total copper loss of $27.5 \mathrm{~W}$.

(iv) The core loss is estimated using the improved generalized Steinmetz equation iGSE [41], because in the LLC converter the excitation voltage on the transformer is a rectangular waveform, and there is no dc bias magnetization.

$$
\begin{aligned}
& P_{\text {core }}=\frac{1}{T_{s}} \int_{0}^{T_{s}} k_{i}\left|\frac{d B}{d t}\right|^{\alpha}(\Delta B)^{\beta-\alpha} d t \\
& k_{i}=\frac{k}{2^{\beta+1} \pi^{\alpha-1}\left(0.2761+\frac{1.7061}{\alpha+1.354}\right)}
\end{aligned}
$$

For PC40, Steinmetz parameters are extracted as $[k=55.85$, $\alpha=1.143, \beta=2.396]$. The core loss is calculated as 11398 $\mathrm{W} / \mathrm{m}^{3}$. The PC40 EER42/42/20-Z core volume is $23700 \mathrm{~mm}^{3}$. Therefore, the total core losses contributed by the three transformers is $0.81 \mathrm{~W}$.

(v) The difference between the total loss and the sum of these aforementioned losses is $3.9 \mathrm{~W}$ and it is denoted by "others". These losses mainly comprise the switching loss of the primary MOSFETs and other parasitics of the circuit.

The power loss in the integrated transformer topology can be calculated as follow

(i) Conduction loss of primary switches:

The MOSFETs utilized in our prototype are Toshiba, TK20E60W, with a drain-source resistance of $0.13 \Omega$. The effective current value through the switches is $1.66 \mathrm{~A}$. The

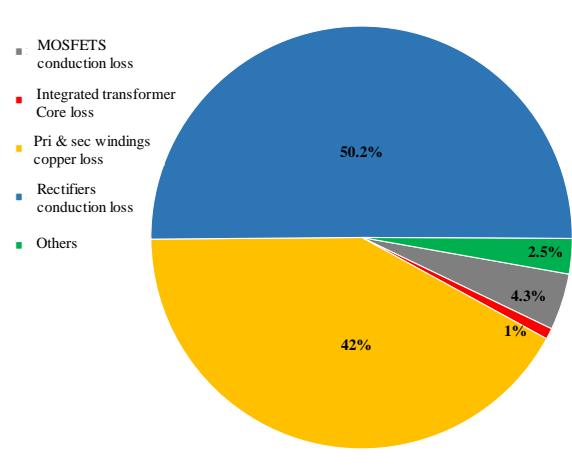

(a)

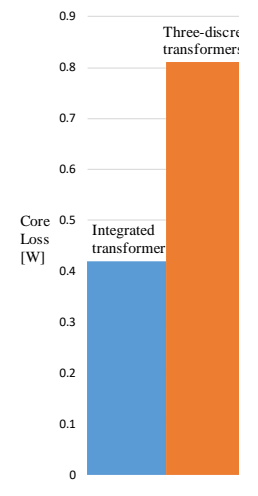

Fig.20 Power losses distribution. (a) Pie chart of the loss distribution in the integrated transformer topology. (b) Core loss comparison between the integrated transformer and the three-discrete transformers.

total conduction loss of the MOSFETs $=6 \times 0.13 \times(1.66)^{2}=$ 2.15W.

Conduction loss of secondary rectifiers: The secondary rectifiers are Schottky diodes VS-100BGQ100 with a $V_{f}$ $=0.6$ at $6.9 \mathrm{~A} \mathrm{rms}$ value of the half-wave secondary current, leading to a total conduction loss of $=6 \times 0.6 \times 6.95=25 \mathrm{~W}$.

(ii) The copper loss of the transformer:

The $a c$ resistance of the transformers primary winding was measured as $2.15 \Omega$ and for the secondary winding is $0.31 \Omega$, leading to a total copper loss of $20.8 \mathrm{~W}$.

(iii) The core loss is calculated based on iGSE [41] as 10387 $\mathrm{W} / \mathrm{m}^{3}$. The PC40 EC70x69x16 core volume is $40420 \mathrm{~mm}^{3}$. Therefore, the total core losses contributed by the three transformers is $0.42 \mathrm{~W}$.

(iv) The difference between the total loss and the sum of these aforementioned losses is $1.2 \mathrm{~W}$ and it is denoted by "others". These losses mainly comprise the switching loss of the primary MOSFETs and other parasitics of the circuit.

The power loss breakdown is depicted in Fig.20 (a). It is clear that the conduction loss on the rectifiers contributes with the major power loss components, alongside with the transformer's winding copper losses. The integrated transformer topology exhibits a lower core loss than the three discrete transformers, as shown in Fig.20 (b). Nonetheless, the core loss contribution in this circuit topology is small, as the maximum value of flux density has a low value. From the power loss perspective, the integrated transformer topology would be more promising in high-frequency LLC converters, as it will highly reduce the core loss compared to the three discrete transformers

\section{CONCLUSION}

A three-phase LLC resonant converter with a three-phase integrated transformer is proposed. The proposed magnetic core is commercially available and easy to be implemented. The integrated transformer attains a $43 \%$ volume reduction, $28 \%$ weight reduction and an approximate of $16 \%$ cost reduction, compared with the three-discrete transformer topology. Furthermore, it has been proven to be efficient and has a uniform thermal distribution along the magnetic core. The 
proposed integrated transformer topology would be highly beneficial in high-frequency applications, in which keeping the core loss at a minimal value is hard to realize. The FEA simulation and Experimental tests showed a proper operation of the integrated transformer. The authors believe that the merits of the integrated transformer reported in this study would promote the industrial applications of the three-phase LLC resonant converter topologies.

\section{APPENDIX}

\section{A. Controlling the leakage inductance}

The leakage inductance can be controlled by inserting a flexible magnetic material between the primary and the secondary. If a low values of leakage inductances is targeted, the air shall be the medium between the primary and secondary windings. The air reluctance is much higher than a magnetic material with a high permeability. Therefore, the leakage flux encounters a higher resistance with the air, as a medium between the primary and the secondary. Adjusting the space between the primary and secondary would result in controlling the leakage value within a specific range. However, inserting a flexible magnetic material between the primary and secondary windings increases the leakage flux, and hence the leakage inductance. In other words, the leakage encounters a path with low reluctance. Targeting a higher or lower value of leakage inductance can be controlled by adjusting the thickness or the permeability of the flexible sheet. The higher the thickness, the more leakage can be realized. As an example to alter the leakage inductance of the integrated transformer, a flexible magnetic sheet had been inserted between the primary and the secondary windings. The magnetic sheet is TDK Flexield (part number IFL12-100NB300x200), with a magnetic permeability of 180 and thickness of $0.1 \mathrm{~mm}$, as shown in Fig.21. The leakage inductance has increased to reach a value of $56.4 \mu \mathrm{H}$, instead of $35.3 \mu \mathrm{H}$.

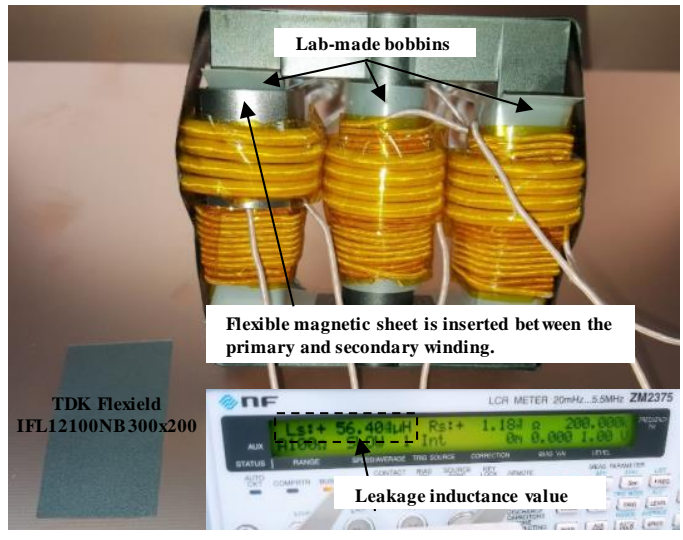

Fig.21 Inserting a magnetic sheet between the windings to purposefully to alter the leakage inductance value.

\section{ACKNOWLEDGMENT}

The authors would like to thank David Sanchez from TDK US and Keigo Higashida from TDK Japan for providing us with magnetic sheet samples, which helped us to conduct part of this research. Furthermore, we would like also to thank the five anonymous reviewers for providing us with many insightful comments and suggestions, which helped us to improve the quality of this manuscript.

\section{REFERENCES}

[1] Z. Liu, X. Huang, M. Mu, Y. Yang, F. C. Lee and Q. Li, "Design and evaluation of GaN-based dual-phase interleaved $\mathrm{MHz}$ critical mode PFC converter," in IEEE Energy Conversion Congress and Exposition (ECCE), Pittsburgh, PA, pp. 611-616, 2014.

[2] Weimin Zhang; Yu Long; Zheyu Zhang; Wang, F.; Tolbert, L.M.; Blalock, B.J.; Henning, S.; Wilson, C.; Dean, R., "Evaluation and comparison of silicon and gallium nitride power transistors in LLC resonant converter," in Energy Conversion Congress and Exposition (ECCE), 2012 IEEE, pp.1362-1366, 15-20 Sept. 2012.

[3] M. Kanechika, T. Uesugi and T. Kachi "Advanced SiC and GaN Power Electronics for Automotive Systems" in Electron Devices Meeting (IEDM), San Francisco, CA, pp.1351-1354, Dec. 2010.

[4] M. Hirakawa, M. Nagano, Y. Watanabe, K. Andoh, S. Nakatomi and S. Hashino, "High Power Density DC/DC Converter using the CloseCoupled Inductors", in Proc. IEEE Energy Conver. Cong. and Expo. (ECCE), Sep. 2009, pp. 1760-1767.

[5] M. Pavlovsky', G. Guidi, and Atsuo Kawamura, "Assessment of Coupled and Independent Phase Designs of Interleaved Multiphase Buck/Boost DC-DC Converter for EV Power Train", IEEE Trans. on Power Electron., Vol. 29, No. 6, pp. 2693-2704, Jun. 2014

[6] K. J. Hartnett, J. G. Hayes, M. G. Egan and M. S. Rylko, "CCTT-Core Split-Winding Integrated Magnetic for High-power DC-DC Converters", IEEE Trans. on Power Electron., Vol. 28. Nov. 2013. pp. 4970-4984,

[7] Q. Li, Y. Dong, F. C. Lee, and D. J. Gilham, "High-Density Low-Profile Coupled Inductor Design for Integrated Point-of-Load Converters", IEEE Trans. on Power Electron., Vol. 28, No. 1, pp. 547-554. Jan. 2012.

[8] J. Imaoka, S. Kimura, Y. Itoh, W. Martinez, M. Yamamoto, M. Suzuki, and K. Kawano, "Feasible Evaluations of Coupled Multilayered Chip Inductor for POL Converters", IEEJ J. of Ind. App., Vol. 4, No. 3, pp. 126-135. May. 2015.

[9] K. J. Hartnett, J. G. Hayes, M. G. Egan, M.S. Rylko, B. J. Barry and J. W. Masłon,, "Comparison of 8-kW CCTT IM and Discrete Inductor Interleaved Boost Converter for Renewable Energy Applications", IEEE Trans. on Ind. App., Vol. 51, No. 3, pp.2455-2469, May. 2015.

[10] T. Qian and B. Lehman, "Coupled Input-Series and Output-Parallel Dual Interleaved Flyback Converter for High Input Voltage Application", IEEE Trans. on Power Electron., Vol. 23, No. 1, pp. 88-95. Feb. 2008.

[11] F. Forest, E. Labouré, T. A. Meynard and J. Huselstein, "Multicell Interleaved Flyback Using Intercell Transformers", IEEE Trans. on Power Electron., Vol. 22, No. 5, pp. 1662-1671. Sep. 2007.

[12] L. Wong, Y. Lee, D. K. Cheng, and M. H. L. Chow, "Two-Phase Forward Converter using an Integrated Magnetic Component", IEEE Trans. on Aerospace and Electron. Sys., Vol. 40, No.4, pp.1294-1310 Sep. 2004.

[13] Y. Su, D. Hou, F. C. Lee and Q. Li, "Low Profile Coupled Inductor Substrate with Fast Transient Response", in Proc. of IEEE Applied Power Electron. Conf. and Expo., (APEC), Mar. 2015. pp. 1161-1168.

[14] Mostafa Noah, Jun Imaoka, Yuki Ishikura, Kazuhiro Umetani, and Masayoshi Yamamoto, "Review of Current Balance Mechanism in Multiphase LLC Resonant Converters", in Proc. IEEE International Symposium on Industrial Electronics (ISIE 2018), Cairns, Australia, June 2018.

[15] H. Kim, J. Baek, M. Ryu, J. Kim and J. Jung, "The high-efficiency isolated AC-DC converter using the three-phase interleaved LLC resonant converter employing the Y-connected rectifier", IEEE Transactions on Power Electronics, Vol. 29, No. 8, August 2014.

[16] K. Murata, F. Kurokawa, "An interleaved PFM LLC resonant converter with phase-shift compensation," IEEE Transactions on Power Electronics, Vol. 31, No. 3, pp. 2264-2272, March 2016.

[17] E. Orietti, P. Mattavelli, G. Spiazzi, C. Adragna, and G. Gattavari, "Current sharing in three phase LLC interleaved resonant converter," in Proc. IEEE Energy Convers. Congr. Expo. (ECCE), pp. 1145-1152, Sep. 2009. 
[18] Y. Nakakohara, H. Otake, T. Evans, T. Yoshida, M. Tsuruya and K. Nakahara, "Three-phase LLC series resonant DC/DC converter using SiC MOSFETs to realize high-voltage and high-frequency operation," IEEE Transactions on Industrial Electronics, Vol. 63, No. 4, pp. 2103-2110, April 2016.

[19] H. Wand, Y. Chen, Y. Liu, J. Afsharian and Z. Yang, "A passive current sharing method with common inductor multi-phase LLC resonant converter", IEEE Trans. On power electronics, Vol. PP, No.99, pp.1-1 2016.

[20] H. Wand, Y. Chen, Y. Qiu, P. Fang, Y. Zhang, L. Wang and Y. Liu,“A common capacitor multi-phase LLC converter with passive current sharing ability", IEEE Trans. On power electronics, Vol. PP, No.99, pp.11 Jan. 2017.

[21] H. Wand, Y. Chen, Y. Liu, J. Afsharian and Z. Yang, "A common inductor multi-phase LLC converter", in Proc. IEEE Energy Convers. Congr. Expo. (ECCE), pp. 548-555, Sep. 2015.

[22] M. Smit, J. Ferreria, J. Wyk and M. Ehsani, "An Ultrasonic Series Resonant Converter with Integrated L-C-T," IEEE Trans. Power Electron., vol.10, no.1, pp. 25-31, Jan 1995.

[23] W. Liu, J. Wyk, "Design of Integrated LLCT Module for LLC Resonant Converter," in Proc. IEEE Appl. Power Electron Conf., 2005, pp. 362368.

[24] Y. Zhang, D. Xu, K. Mino and K. Sasagawa,"1MHz-lkW LLC Resonant Converter with Integrated Magnetics," in Proc. IEEE Appl. Power Electron Conf., 2007, pp. 1630-1635.

[25] Yang, B., Chen, R., and Lee, F.C.: 'Integrated magnetics for LLC resonant converter'. IEEE Applied Power Electronics Conf. Exposition (APEC) 2002, Dallas, TX, USA, March 2002, pp. 346-351.

[26] Zhang, Y., Xu, D., Mino, K., and Sasagawa, K.: '1 MHz-1 kW LLC resonant converter with integrated magnetics'. IEEE Applied Power Electronics Conf. Exposition (APEC) 2007, Anaheim, CA, USA, February 2007, pp. 955-961

[27] Liu, W., and van Wyk, J.D.: 'Design of integrated LLCT module for LLC resonant converter'. IEEE Applied Power Electronics Conf. Exposition (APEC) 2005, Austin, TX, USA, March 2005, pp. 362-368

[28] Mostafa Noah, Kazuhiro Umetani, Jun Imaoka, and Masayoshi Yamamoto, "Winding Orientation Method to Minimise the Secondary Leakage of a Gapped Transformer Utilised in LLC Resonant Converter" IET Electronics Letters, Volume:54, Issue:3, Page:157-159, February 2018.

[29] W. Martinez, M. Noah, S. Endo, K. Nanamori, S. Kimura, M. Yamamoto, J. Imaoka and K. Umetani, "Three-phase LLC Converter with Integrated Magnetics," in Proc. IEEE Energy Conver. Cong. and Expo. (ECCE),pp. 1-8, Sep. 2016.

[30] M. Noah, K. Umetani, S. Endo, H. Ishibashi, J. Imaoka, and M. Yamamoto, "A Lagrangian Dynamics Model of Integrated Transformer Incorporated in a Multi-phase LLC Resonant Converter," in Proc. IEEE Energy Conver. Cong. and Expo. (ECCE),pp. 1-8, Sep. 2017.

[31] M. Noah, K. Umetani, J. Imaoka, M. Yamamoto.: 'Lagrangian dynamics model and practical implementation of an integrated transformer in multiphase LLC resonant converter', IET on Power Electronics 2017, doi: 10.1049/ietpel.2017.0485

[32] M. Noah, et al.:" A Current Sharing Method Utilizing Single Balancing Transformer for a Multiphase LLC Resonant Converter with Integrated Magnetics," IEEE Journal of Emerging and Selected Topics on Power Electronics, Volume: 6, Issue:2, Page:977-992, June 2018.

[33] M. Noah, S. Kimura, S. Endo, M. Yamamoto, J. Imaoka, K. Umetani, W. Martinez "A Novel Three-phase LLC Resonant Converter with Integrated Magnetics for Lower Turn-off losses and Higher Power Density," Conf. Proc.- IEEE Appl. Power Electron. Conf. Expo. (APEC), pp. 1-8, March, 2017.

[34] Jun Zhang, William Gerard Hurley, and Werner Hugo Wölfle, "Gapped Transformer Design Methodology and Implementation for LLC Resonant Converters," IEEE Transaction on Industry Applications, Vol. 52, No. 1, pp. 342-350, Jan./Feb. 2016

[35] W. G. Hurley and W. H. Wolfle, Transformers and inductors for power electronics. Theory, Design and Applications. Chichester, U.K.: Wiley, 2013.

[36] M. Noah, S. Endo, S. Kimura, M. Yamamoto, J. Imaoka, and K. Umetani, and E. Hiraki“"An Investigation into a Slight-Variation of the Transformer
Effective Permeability in LLC Resonant Converter" Record of IEEE 19th Conference on Power Electronics and Applications, EPE 2017, Sep. 2017.

[37] Texsas instrument, "Section 4 - Power Transformer Design". Available: https://www.ti.com/lit/m1/slup126/slup126.pdf

[38] Large size ferrite cores for high power, TDK [online]. Available: https://product.tdk.com/info/en/catalog/datasheets/ferrite_mz_large_e_e n.pdf.

[39] Ferrite core for switching power supplies, TDK [online]. Available: product.tdk.com/info/en/catalog/datasheets/ferrite_mz_sw_e_en.pdf.

[40] Allied Electronics Co. Ltd, USA, "Passive components" [online]. Available: http://www.alliedelec.com/passive-components/

[41] K. Venkatachalam, C. R. Sullivan, T. Abdallah, and H. Tacca, "Accurate prediction of ferrite core loss with nonsinusoidal waveforms using only Steinmetz parameters," in Proc. IEEE Workshop on computers in Power Electronics, pp. 36-41, June 2002.

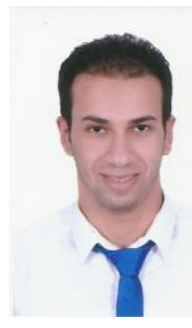

Mostafa Noah (S'15) received his M.Sc. degree in Electrical Engineering from Cairo University, Egypt in 2014. From 2009 to 2015, he was an Electrical Design Engineer with SCG and Dar Al-Handasah. From 2015 to 2017, he was a Research Assistant at the Power Electronics Lab of Shimane University, Japan. In spring 2018, he was with Panasonic, Osaka, Japan, as an intern. Currently, he is with the Power Electronics Lab of Nagoya University, Japan, where he is pursuing the $\mathrm{PhD}$. His research interests focus on proposing new magnetic solutions to increase the efficiency and power density of DC/DC converters and LLC resonant converters.

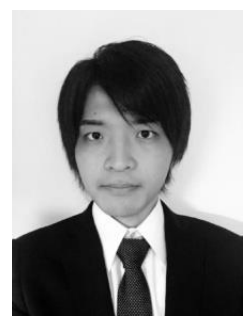

Shota Kimura received his M.S. and Ph. D degrees in mechanical, electrical and electronic engineering from Shimane University, Shimane, Japan, in 2015 and 2018 respectively. His research interests include design of integrated magnetic components for high power density DC-DC converter.

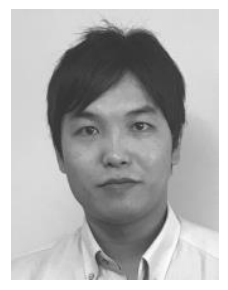

Jun Imaoka (S'11-M'15) received his M.S. and $\mathrm{Ph}$. D degrees in electronic function and system engineering from Shimane University in 2013 and 2015 respectively. From Oct. 2015 to March 2018, he was with Kyushu University as an Assistant Professor, Fukuoka, Japan. Currently, he is assistant professor in Nagoya university, Japan. His research interests include design of integrated magnetic components, modeling for high power density power converters, thermal management for power converters, magnetic material application, EMI of switching power supply.

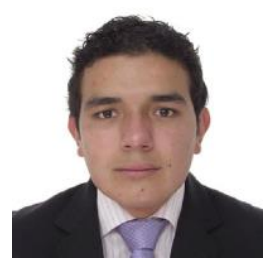

Wilmar Martinez (S'09-M'16) received the B.S. degree in electronics engineering and the M.Sc. degree in electrical engineering from Universidad Nacional de Colombia, Bogota, Colombia, in 2011 and 2013, respectively, and the Ph.D. degree in electronic function and system engineering from Shimane University, Matsue, Japan, in 2016. He worked as a Postdoctoral Researcher at the Toyota Technological 
Institute, Nagoya, Japan, and at Aalto University, Espoo, Finland in 2016 and 2017, respectively. He is currently Assistant Professor at KU Leuven - EnergyVille, Belgium. His research interests include multi-objective optimization of power converters, evaluation of iron losses at high carrier frequency in electric motors, and high power density converters for electric vehicles, renewable energies, and smart grids.

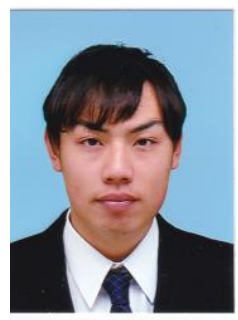

Shun Endo received the B.S. degree in electrical and electronic systems engineering from Shimane University, Shimane, Japan, in 2015. He received his master degree in mechanical, electrical and electronic engineering at Shimane University, Shimane, Japan in 2018. His research interests include the control system of the

\section{DC/DC converters.}

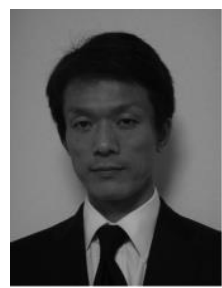

Masayoshi Yamamoto (M'11) received his M.S. and Ph.D. degree in science and engineering from Yamaguchi University, Yamaguchi, Japan in 2000 and 2004 respectively. From 2004 to 2005, he was with Sanken Electric Co., Ltd., Saitama, Japan. Since 2006, he joined Interdisciplinary Faculty of Science and Engineering in Shimane University, Japan, as an Associate Professor. Currently, he is a Professor at Institute of Materials and Systems for Sustainability (IMaSS), Nagoya University, Japan. His research interests include power supply for HEV (boost converter, buck converter, 3-phase inverter, digital control), charging system for $\mathrm{EV}$, highfrequency power supply using $\mathrm{GaN}$ and $\mathrm{SiC}$ power devices, LED illumination system for a tunnel, EMI of switching power supply, and wireless power transfer. Dr. Yamamoto holds 12 U.S. and Japanese patents, has published 9 books, and has published over 140 refereed technical journal and conference papers.

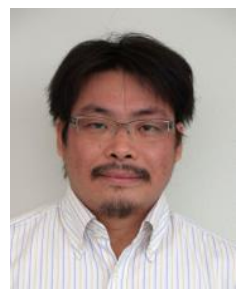

Kazuhiro Umetani (M'12) was born in Kobe, Japan. He received the M.S. and Ph. D. degree in geophysical fluid dynamics from Kyoto University, Kyoto, Japan in 2004 and 2007, respectively. In 2015, he received the second Ph.D. degree in electrical engineering from Shimane University, Japan.

From 2007 to 2008, he was a Circuit Design Engineer for Toshiba Corporation, Japan. From 2008 to 2014, he was with the Power Electronics Group in DENSO Corporation, Japan. $\mathrm{He}$ is currently an Assistant Professor at Okayama University, Okayama, Japan. His research interests include new circuit configurations in power electronics and power magnetics for vehicular applications.

Dr. Umetani is a member of the Institute of Electrical Engineers of Japan and the Japan Institute of Power Electronics. 